\title{
Population structure, adaptation and divergence of the meadow spittlebug, Philaenus spumarius (Hemiptera, Aphrophoridae), revealed by genomic and morphological data
}

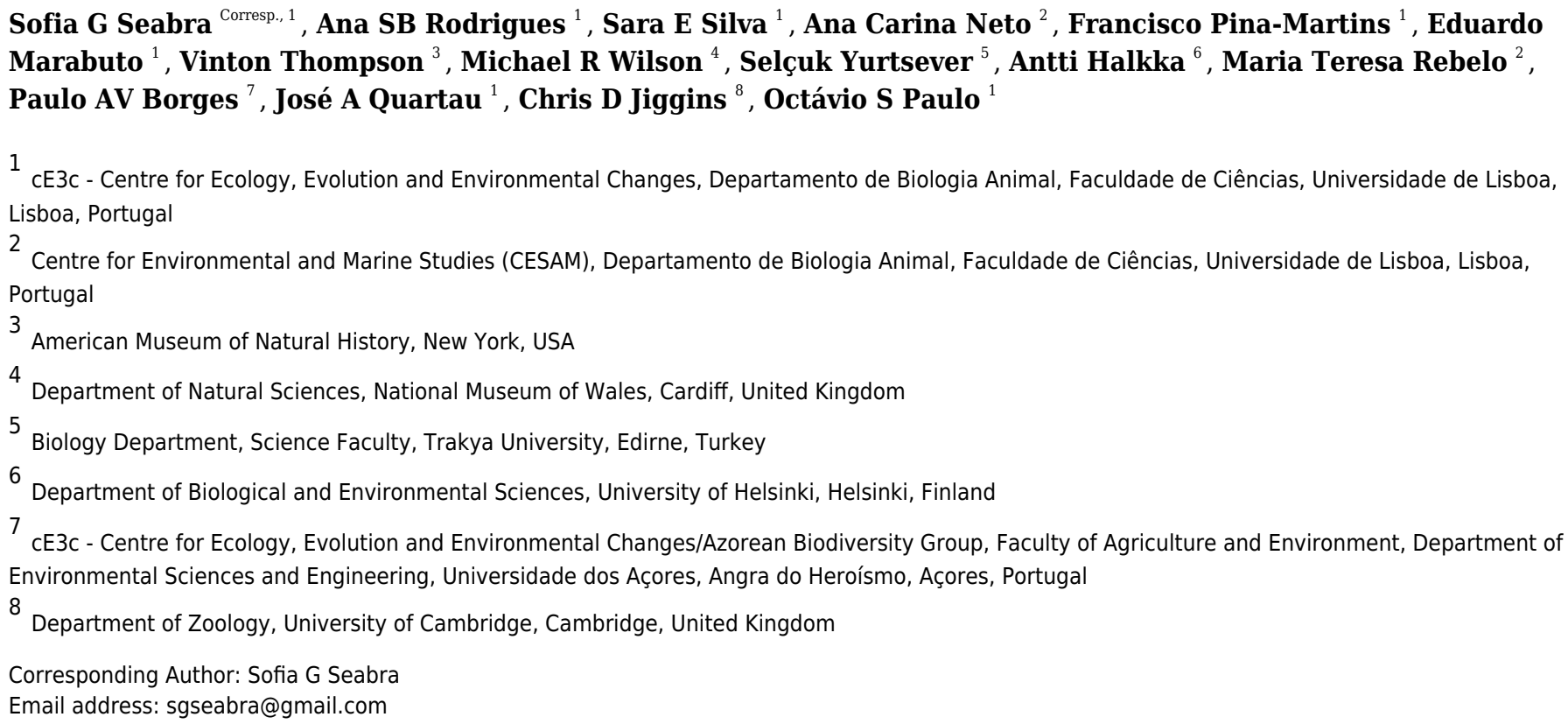

Understanding patterns of population differentiation and gene flow in insect vectors of plant diseases is crucial for the implementation of management programs of disease. We investigated morphological and genome-wide variation across the distribution range of the spittlebug Philaenus spumarius (Linnaeus, 1758) (Hemiptera, Auchenorrhyncha Aphrophoridae), presently the most important vector of the plant pathogenic bacterium Xylella fastidiosa in Europe. We found genome-wide divergence between $P$. spumarius and a very closely related species, $P$. tesselatus Melichar, 1899, at RAD sequencing markers. The two species may be identified by the morphology of male genitalia but are not differentiated at mitochondrial COI, making DNA barcoding with this gene ineffective. This highlights the importance of using integrative approaches in taxonomy. We detected admixture between $P$. tesselatus from Morocco and $P$. spumarius from the Iberian Peninsula, suggesting gene-flow between them. Within $P$. spumarius, we found a pattern of isolation-by-distance in European populations, likely acting alongside other factors restricting gene flow. Varying levels of co-occurrence of different lineages, showing heterogeneous levels of admixture, suggest other isolation mechanisms. The transatlantic populations of North America and Azores were genetically closer to the British population analysed here, suggesting an origin from North-Western Europe, as already detected with 
mitochondrial DNA. Nevertheless, these may have been produced through different colonization events. We detected SNPs with signatures of positive selection associated with environmental variables, especially related to extremes and range variation in temperature and precipitation. The population genomics approach provided new insights into the patterns of divergence, gene flow and adaptation in these spittlebugs and led to several hypotheses that require further local investigation. 


\section{Population structure, adaptation and divergence of the}

8 Sofia G Seabra $^{1 *}$, Ana SB Rodrigues ${ }^{1}$, Sara E Silva ${ }^{1}$; Ana Carina Neto ${ }^{2}$; Francisco Pina-Martins ${ }^{1}$;

9 Eduardo Marabuto ${ }^{1}$; Vinton Thompson ${ }^{3}$; Michael R. Wilson ${ }^{4}$; Selcuk Yurtsever ${ }^{5}$; Antti Halkka ${ }^{6}$;

10 Maria Teresa Rebelo ${ }^{2}$, Paulo AV Borges 7 ; José A Quartau ${ }^{1}$; Chris D Jiggins ${ }^{8}$; Octávio S Paulo ${ }^{1}$

${ }^{1} \mathrm{cE} 3 \mathrm{c}$ - Centre for Ecology, Evolution and Environmental Changes, Departamento de Biologia Animal, Faculdade de Ciências, Universidade de Lisboa, Lisboa, Portugal.

${ }^{2}$ Centre for Environmental and Marine Studies (CESAM), Departamento de Biologia Animal, Faculdade de Ciências, Universidade de Lisboa, Lisboa, Portugal.

${ }^{3}$ American Museum of Natural History, New York, USA

${ }^{4}$ Department of Natural Sciences, National Museum of Wales, Cardiff, United Kingdom

${ }^{5}$ Biology Department, Science Faculty, Trakya University, Edirne, Turkey

${ }^{6}$ Department of Biological and Environmental Sciences, University of Helsinki, Helsinki, Finland

${ }^{7} \mathrm{cE} 3 \mathrm{c}$ - Centre for Ecology, Evolution and Environmental Changes/Azorean Biodiversity Group, Faculty of Agriculture and Environment, Department of Environmental Sciences and Engineering, Universidade dos Açores, Angra do Heroísmo, Açores, Portugal

${ }^{8}$ Department of Zoology, University of Cambridge, Cambridge, United Kingdom

Corresponding Author: 
Sofia G. Seabra ${ }^{1}$

cE3c - Centre for Ecology, Evolution and Environmental Changes, Departamento de Biologia Animal, Faculdade de Ciências, Universidade de Lisboa, Campo Grande, Edifício C2, 1749-016 Lisboa, Portugal. Email address: sgseabra@gmail.com

\section{Abstract}

Understanding patterns of population differentiation and gene flow in insect vectors of plant diseases is crucial for the implementation of management programs of disease. We investigated morphological and genome-wide variation across the distribution range of the spittlebug Philaenus spumarius (Linnaeus, 1758) (Hemiptera, Auchenorrhyncha Aphrophoridae), presently the most important vector of the plant pathogenic bacterium Xylella fastidiosa in Europe. We found genome-wide divergence between $P$. spumarius and a very closely related species, $P$. tesselatus Melichar, 1899, at RAD sequencing markers. The two species may be identified by the morphology of male genitalia but are not differentiated at mitochondrial COI, making DNA barcoding with this gene ineffective. This highlights the importance of using integrative approaches in taxonomy. We detected admixture between $P$. tesselatus from Morocco and $P$. spumarius from the Iberian Peninsula, suggesting gene-flow between them. Within $P$. spumarius, we found a pattern of isolation-by-distance in European populations, likely acting alongside other factors restricting gene flow. Varying levels of co-occurrence of different lineages, showing heterogeneous levels of admixture, suggest other isolation mechanisms. The transatlantic populations of North America and Azores were genetically closer to the British population analyzed here, suggesting an origin from North-Western Europe, as already detected with mitochondrial DNA. Nevertheless, these may have been produced through different colonization events. We detected SNPs with signatures of positive selection associated with environmental variables, especially related to extremes and range variation in temperature and precipitation. The population genomics approach provided new insights into the patterns of divergence, gene flow and adaptation in these spittlebugs and led to several hypotheses that require further local investigation. 


\section{Introduction}

63 Speciation involves the evolution of reproductive isolation and the buildup of genetic

64 differentiation through selection and drift, but gene flow can counteract such divergence by

65 homogenizing allelic variation and also by allowing recombination to oppose or break

66 associations between loci underlying isolating traits (Smadja \& Butlin, 2011; Sousa \& Hey,

67 2013). However, several mechanisms may favour divergence in the face of gene flow, such as

68

69

70

71

72

73

74

75

76

77

78

79

80

81

82

83

84

85

86

87

88

89

90

91 ecologically driven selection or sexual selection (Smadja \& Butlin, 2011; Nosil, 2012). According to the genic model of speciation, at the start of the speciation process, and in the presence of gene flow, a few localized regions in the genome subject to divergent selection will differentiate, while the remaining genome continues to be freely exchanged between populations (Wu, 2001). Genome-wide analyses have allowed the detection of these "genomic islands" of differentiation in several systems (e.g., Malinsky et al., 2015; Vijay et al., 2017), although other processes not related to speciation or reproductive isolation may also be responsible for them, such as linked selection, variable recombination rates and/or density of targets of selection (Wolf \& Ellegren, 2017). As populations diverge through the action of selection and drift, a genomewide differentiation will emerge and eventually lead to full reproductive isolation and diversification. Designated species may thus lie somewhere in this "speciation continuum", with different levels of divergence and gene flow (Hendry, Bolnick, Berner, \& Peichel, 2009; Peccoud, Ollivier, Plantegenest, \& Simon, 2009; Renaut et al., 2012; Riesch et al., 2017).

Distinguishing taxa and understanding the patterns of gene flow and local adaptation in insect species that transmit diseases are crucial for better management of those diseases (Busvine, 1980; Pélissié, Crossley, Cohen, \& Schoville, 2018; Bahrndorff et al., 2020). Philaenus spumarius (Linnaeus, 1758) (Insecta, Hemiptera, Auchenorrhyncha, Aphrophoridae), the meadow spittlebug, is a xylem-feeding vector of Xylella fastidiosa Wells et al. 1987, a plant pathogenic bacterium of South American origin that is emergent in Europe (Saponari et al., 2014). Olive quick decline syndrome (OQDS), caused by $X$. fastidiosa, was first detected in Apulia, southern Italy in 2013, where it soon became clear that P. spumarius was the most important vector (Saponari et al., 2014; Cornara et al., 2017). Since then, X. fastidiosa has been detected in several other European countries and is a cause for major concern (EFSA et al., 
92 2019). $X$. fastidiosa is native to the Americas, where it causes important diseases such as Pierce's

93 disease of grapevine, citrus variegated chlorosis, almond leaf scorch and several others in 94 perennial crops and ornamental plants (Baldi \& La Porta, 2017). There the main vectors are 95 sharpshooters (another xylem-feeding Auchenorrhyncha group, the Cicadellidae Cicadellinae), 96 while spittlebugs appear to have a small but perhaps not negligible epidemiological importance 97 (Almeida et al., 2019; Cornara et al., 2019; Beal et al., 2021). One of the main vectors of Pierce's 98 disease of grapevines in California is the glassy-winged sharpshooter Homalodisca vitripennis 99 (Germar, 1821). It is native to the southern United States and it became established in late 1990's 100 in California, being a costly invasive species to agriculture. Population genetic structure studies 101 based on DNA fingerprinting and mitochondrial DNA on this species have revealed highly 102 differentiated geographic groups in the natural range and indicated that the likely sources of the 103 California insects were in Texas (Léon, Jones \& Morgan, 2004; Smith, 2005). This inspired 104 further work in Texas, which led to a better understanding of the natural population dynamics 105 (Yoon et al., 2014). This demonstrates the potential importance of knowledge of the population 106 genetic structure of $P$. spumarius for understanding the dynamics of the spread of $X$. fastidiosa in 107 Europe. Since the vectors are the only means of natural dissemination of $X$. fastidiosa (Sicard et 108 al., 2018), this information is crucial for the successful management of this pathogen and should be included in models of risk assessment (EFSA Panel on Plant Health, 2015).

P. spumarius is a polyphagous xylem-feeding insect, widespread in the Holarctic, whose nymphs produce a protective foam (spittle masses) from their liquid excretion. Humidity and temperature are particularly limiting in the earlier nymphal stages (Weaver \& King, 1954). In general, adults

114 live during one reproductive season in spring/summer, and then at the end of summer/autumn the 115 females oviposit and the eggs overwinter in the vegetation until they hatch in the following 116 spring/summer (Halkka \& Halkka, 1990). This species is thought to have a Palaearctic origin, 117 and to have recently colonized North America, the Azorean islands, Hawaii and New Zealand. 118 These introductions were likely mediated by humans (Halkka \& Halkka, 1990; Rodrigues et al., 119 2014), although natural colonization cannot be excluded for the S. Miguel island in the Azores 120 (Borges et al., 2018; Rodrigues et al., 2014) as the populations in this island are restricted to to 121 high elevation native vegetation of the oriental and geologically oldest part of this island. In parts 122 of North America it has been a crop pest (Weaver \& King, 1954), but surveys of the spittle 
123 masses along coastal California have revealed a recent population decline of this species, very

124 accentuated in some places (Karban \& Strauss, 2004; Karban \& Huntzinger, 2018). The

125 population in the Wonalancet, New Hampshire site sampled for this report has also declined (V

126 Thompson, unpublished data).

127

128 Previous studies based on mitochondrial and nuclear DNA genes have revealed the major 129 phylogeographic patterns in Philaenus spumarius (Maryańska-Nadachowska, Kajtoch \& 130 Lachowska, 2011; Rodrigues et al., 2014). Two main mitochondrial lineages have initially 131 diverged during the Pleistocene: the "Western", currently found in the Mediterranean region and 132 also in Central and Northern Europe, and the "North-Eastern", currently found from Eastern Asia 133 to Central and Northern Europe. The "Western" lineage is further differentiated into sublineages: 134 the "Western", predominant in the Iberian Peninsula but also in western parts of Central and 135 Northern Europe; and the "Eastern-Mediterranean" present in the Balkans and Middle East and 136 others around Black Sea and in the Caucasus (Maryańska-Nadachowska et al., 2011; Rodrigues 137 et al., 2014). These lineages also co-occur in several contact zones (Lis et al., 2014; Rodrigues et 138 al., 2014). The occurrence of different infection rates of the maternally inherited endosymbiont Wolbachia in the different lineages of $P$. spumarius has pointed to a possible mechanism to explain the maintenance of genetic differentiation in the Carpathians contact zone (Lis et al., 2015). Previous studies have also revealed close relationships and even shared haplotypes

142 between samples from North America, Azores, New Zealand and those from Great Britain 143 (Rodrigues et al., 2014), indicating a recent human-assisted colonization, as previously suggested 144 for North America and New Zealand (Hamilton, 1979; Yurtsever, 2002).

146 Seven other species of the genus Philaenus occur in the Mediterranean area, having a much more 147 restricted distribution ranges, which partially overlapping that of $P$. spumarius (Drosopoulos, 148 2003; Maryańska-Nadachowska et al., 2010). One such species is P. tesselatus Melichar, 1889, 149 which was originally described from Tunisia and was later synonymized with $P$. spumarius 150 (Nast, 1972), being considered a geographic subspecies. Later the synonymy was re-assessed 151 based on morphological evaluation, with the best diagnostic characters being the size and shape 152 of the appendages of the male aedeagus (Drosopoulos \& Quartau, 2002). However, geographic variation in the curvature of the aedeagal apical appendages in $P$. spumarius has been reported in 
154 both Europe and North America (Wagner, 1955; 1959; Hamilton, 1979). Such variation in 155 aedeagus structure within P. tesselatus is still largely unexplored (Drosopoulos \& Quartau, 156 2002). Recent genetics studies based on mitochondrial cytochrome c oxidase I (COI) and 157 cytochrome b (cytB), as well as on nuclear internal transcribed spacer 2 (ITS2) and elongation 158 factor 1-alpha (EF-1alpha) DNA sequence analysis have questioned the species status of $P$. 159 tesselatus, since individuals showing $P$. tesselatus-like male genitalia have the same or very 160 similar sequences to P. spumarius (Maryańska-Nadachowska et al., 2011; Rodrigues et al., 161 2014). It is expected that genome-wide markers will provide greater resolution to understand the 162 divergence between these cryptic species. Delimitation of species boundaries is a difficult 163 taxonomic endeavour but it is now widely recognised that an integrative taxonomic approach 164 should include phenotypic, genetic (with a large number of nuclear and mitochondrial markers), 165 and ecological data (Edwards \& Knowles, 2014; Tonzo, Papadopoulou \& Ortego, 2019).

166

167 168 169 170 171

80

In this study, we applied restriction site-associated DNA sequencing (RAD-seq), a reducedrepresentation sequencing approach that simultaneously discovers and genotypes thousands of single nucleotide polymorphisms for a large number of individuals (Baird et al., 2008; Andrews et al., 2016). We had three main objectives: i) to characterize the morphological (appendages of male aedeagus) and genome-wide divergence between $P$. spumarius and P. tesselatus; ii) characterise the patterns of genome-wide differentiation of $P$. spumarius populations across the distribution range of the species; and iii) detect local adaptation by finding genomic regions under selection and associated with environmental variation. The information on gene flow between populations and on the environmental factors associated with local adaptation, as well as on the most appropriate diagnostic methods for the identification of the closely related $P$. spumarius and $P$. tesselatus, will be important for future risk assessment of $X$. fastidiosa spread in Europe.

\section{Materials \& Methods}




\section{Sampling}

183 Adults and nymphs of Philaenus spumarius were collected in 2010 and 2011 from eight

184 populations (Figure 1) across the distribution range of the species: Cerkes, Anatolia, Turkey

185 (TUR); Mount Parnassus, Greece (GRE); Haapanaki-Keuruu, Finland (FIN); Fitou, South of

186 France (FRAN); Gouveia/Fontanelas, Sintra, Portugal (POR); Aberdare, South Wales, United

187 Kingdom (UK); S. Miguel island, Azores (AZO); Wonalancet, New Hampshire, United States of

188 America (USA). P. tesselatus was sampled in Morocco (MOR), from three main localities, near

189 Azrou, near Rabat and near Ceuta. In total, 170 specimens were sequenced, including $20-22$

190 individuals from each sampling site except Morocco, from where only 7 specimens were

191 included (Supplementary Table S1). Since sampling in this last location was initially intended for

192 a phylogeographic characterization (Rodrigues et al., 2014), only a few individuals were

193 collected from each site.

194

195 Nymphs were hand collected from the spittle masses they produce. Adults were collected by 196 sweeping the vegetation with an entomological net. Both nymphs and adults occur and feed on

197 large numbers of host plant species and no particular hosts were selected during sweeping and

198 hand collection. Efforts by others to show associations between common hosts and the 199 genetically determined color polymorphism gave negative results (Halkka et al., 1967) and we 200 know of no evidence suggesting host-specific genetic differentiation.

201

202 Insects were preserved in absolute or $96 \%$ ethanol until they were subjected to DNA extraction 203 after up to one year.

204

205

\section{Morphological characters}

206 Philaenus species distinction based on the morphology of male genitalia was accomplished for a 207 subset of 38 males from across all populations, except the AZO and FRAN, for which only 208 immature individuals or females were collected. Nine additional males from MOR, POR and 209 TUR were included to increase morphological sample size, but were not used for genetic 210 analyses (Supplementary Table S1). Preparation and measurements of male genitalia were done 211 as detailed in Supplementary Material - Supplementary Information 1. 
213 Five variables calculated from the nine measurements (Figure 2) were used in the morphometric 214 analysis: total length of aedeagus (TotLen), mean length of lower appendages (LowLen), mean 215 length of middle appendages (MidLen), mean length of upper appendages (UpLen), mean 216 curvature of upper appendages (UpCur). The mean value of measurements of paired structures 217 was considered instead of both left and right measurements individually to reduce some of the 218 variability and the number of specimens to be dropped out of the analysis due to missing values 219 related to appendages that were occasionally broken or tilted during aedeagus removal.

A Principal Component Analysis (PCA) was used to evaluate if morphological characters of the 222 aedeagus could separate Philaenus species and/or populations. PCA was applied to standardised variables (centred by the mean and scaled by the variance), since they were measured in different units. Three specimens were left out of the analysis due to missing values. The analysis was performed in R version 3.4.1 (R Core Team, 2017) using the "prcomp" function and figures were produced using the package "ggplot2" version 3.2.1 (Wickham, 2016).

227

228

DNA extraction and mitochondrial DNA analyses

DNA was extracted from the head and thorax of each specimen using the DNeasy Blood \& Tissue kit (Qiagen) following the manufacturer's instructions and including an RNase A treatment step. Wings and abdomen were not used for DNA extraction to avoid extracting DNA of endosymbionts and parasites. The obtained DNA was assessed for the presence of a high molecular weight band on the agarose gel after electrophoresis, and it was quantified in Qubit 2.0 (Invitrogen), using Qubit dsDNA HS Assay kit.

A subset of 48 specimens from the nine areas were sequenced for mitochondrial DNA 237 (Supplementary Table S1) from which we amplified an $800 \mathrm{bp}$ fragment of the 3'-end of the mitochondrial gene cytochrome $c$ oxidase subunit I (COI) by polymerase chain reaction (PCR). Primers used were: C1-J-2195 (5'-TTGATTTTTTGGTCATCCAGAAGT-3') and TL2-N-3014 (5'-TCCAATGCACTAATCTGCCATATTA-3') (Simon et al., 1994). PCR was performed in a $12.5 \mathrm{uL}$ reaction volume containing: 1x Colorless GoTaq Flexi Buffer, $2 \mathrm{mM} \mathrm{MgCl}, 0.2 \mathrm{mM}$ dNTPs, $0.6 \mathrm{mg} / \mathrm{ml}$ of BSA, $0.5 \mu \mathrm{M}$ of each primer, $0.0375 \mathrm{U}$ GoTaq DNA Polimerase 
244 at $95^{\circ} \mathrm{C}$ for $5 \mathrm{~min}$, followed by 35 cycles of denaturation at $95^{\circ} \mathrm{C}$ for $45 \mathrm{~s}$, annealing at $50^{\circ} \mathrm{C}$ for

$24535 \mathrm{~s}$ and extension at $72^{\circ} \mathrm{C}$ for $2 \mathrm{~min}$, with a final extension period at $72^{\circ} \mathrm{C}$ for $10 \mathrm{~min}$.

246

247 Chromatograms were verified and edited using SEQUENCHER v. 4.0.5 (Gene Codes

248 Corporation), they were aligned using CLUSTAL W on BIOEDIT v. 7.0.9 (Thompson, Higgins, 249 \& Gibson, 1994; Hall, 1999) and subsequently trimmed to the same length. We followed the 250 designation of haplotypes of Rodrigues et al. (2014). A median-joining haplotype network was 251 constructed using POPART version 1.7 (Bandelt, Forster, \& Rohl, 1999; Leigh \& Bryant, 2015). 252

253

254

255

256

257

258

259

260

261

262

263

264

265

266

267

268

269

270

271

272

273

\section{RAD libraries preparation and sequencing}

RAD libraries were prepared using a protocol by Etter et al. (2011), with modifications as in Rodrigues et al. (2016). The restriction enzyme used was SbfI (New England Biolabs). Six libraries were prepared, with 28 to 31 individually barcoded samples multiplexed. The libraries were sequenced on three lanes of an Illumina HiSeq 2000 in paired-end mode $(2 \times 100 \mathrm{bp})$ at Genepool (Ashworth Laboratories) (http://genomics.ed.ac.uk/). The individuals from each population were distributed over the different libraries and lanes to avoid library or lane-specific biases.

\section{Assembly and SNP calling}

The sequence reads from each run were examined by process_radtags from STACKS version 1.45 (Catchen et al., 2013), to remove those with uncalled bases and low-quality scores (phred score lower than 10), to check that the barcode and restriction site were intact in each read and to demultiplex the samples based on the barcode identification. Reads were trimmed at the 3' end, using TRIMMOMATIC v. 0.38 , to keep only 87 bases, since preliminary analyses using the entire read revealed a high number of (possibly false) SNPs at the 3' end after this number of bases (data not shown). This may be due to higher sequencing errors towards the end of the reads characteristic of Illumina sequencing (Dohm et al., 2008). The trimmed reads were de novo assembled into "stacks" (identical sets of reads, called loci) for each individual using the

272 STACKS module ustacks. The minimum depth of coverage to build a stack (-m) was set to 10 , the maximum number of nucleotide differences allowed between stacks to form a locus (-M) was 
274 set to 2 . Then the STACKS module cstacks was used to build a catalog by merging stacks (loci) 275 from multiple individuals, using the default options. The module sstacks was used to match loci 276 from an individual against the catalog. Stacks with very high coverage were removed since they 277 may represent highly repetitive regions and that may include non-orthologous sequences.

278

279 Finally, the populations module was used to create a Variant Call Format (VCF) file with the bi280 281 282 283 284 285

286 287 288

289 290 291 292 293 294 295 296 297 298 299

allelic genotypes of each individual for each variable nucleotide position. The minimum number of populations a locus must be present in to process a locus (-p) was set to the number of populations analyzed (eight or nine, excluding or including Morocco, respectively - see below), the minimum percentage of individuals in a population required to process a locus for that population (-r) was set to $0.5(50 \%)$. Only one SNP per locus was kept, using the option write_random_snp. Other parameters (-M 2, 3 and 6, -m 5 and 10,-n 1 and 4, --min_maf 0.05 or with no min maf) were tested and the differences were assessed by general patterns in the Principal Component Analysis.

The VCF file was then filtered using VCFTOOLS (v 0.1.14) (Danecek et al., 2011), excluding sites with less than $75 \%$ of individuals with genotype (--max-missing 0.75 ) and/or with minor allele count of 2 (--mac 2), to exclude singletons (Linck \& Battey, 2019). In order to exclude overclustered loci, we filtered out those with a mean depth (across individuals) higher than 200x (--max-meanDP 200).

The filtered VCF file with the SNP genotypes was converted into the file formats needed for the different analysis programs using PGDSPIDER 2.0.4.0 (Lischer \& Excoffier, 2012). For conversion of GESTE format to BAYPASS format, we used the script https://github.com/CoBiG2/RAD Tools/blob/master/geste2baypass.py as of commit b99636e.

VCFTOOLS was used to calculate summary statistics of coverage and percentage of missing data. GENETIX v. 4.05 .2 was used to obtain expected and observed heterozygosity, as well as $F_{\text {IS }}$ in each population. Pairwise differentiation between populations $\left(\mathrm{F}_{\mathrm{ST}}\right)$ were calculated in ARLEQUIN 3.5.1.3, and the significance of $\mathrm{F}_{\mathrm{ST}}$ was obtained from permutation tests with 10000 repetitions. Mantel tests between $\mathrm{F}_{\mathrm{ST}} /\left(1-\mathrm{F}_{\mathrm{ST}}\right)$ matrices and the natural logarithm of the 
305

306

307

308

309

310

311

312

313

314

315

316

317

318

319

320

321

322

323

324

325

326

327

328

329

330

331

332

333

334

geographical distance (Rousset, 1997) were performed with ape package version 5.0 (http://apepackage.ird.fr/) in R version 3.4.0, using 9999 permutations.

\section{Population structure}

Principal Components Analysis (PCA) was used as an exploratory tool of the population structure (Novembre \& Stephens, 2008). Computations of PCA were performed in R using package SNPRelate version 1.12.0 (Zheng et al., 2012). Population structure was further examined using the model-based clustering algorithm implemented in STRUCTURE v. 2.3.4 (Falush, Stephens, \& Pritchard, 2003; Pritchard, Stephens, \& Donnelly, 2000). We obtained the coefficients of ancestry using the admixture model and assuming correlated allele frequencies among populations, and $\mathrm{K}$ from 1 to 9, with 10 replicate runs of each, applying 50000 steps of burnin and 1000000 MCMC steps after burnin. STRUCUTRE_THREADER version 1.2.2 (PinaMartins et al., 2017) was used to parallelize the runs and to find the $\mathrm{K}$ best explaining the data by calculating Delta K on STRUCTURE HARVESTER (Evanno, Regnaut, \& Goudet, 2005; Earl \& vonHoldt, 2012). CLUMPP version 1.1.2 (Jakobsson \& Rosenberg, 2007) was then used to obtain the optimal alignment of ancestry proportions, by permuting the 10 replicate runs of STRUCTURE for each value of $K$.

The complete dataset consisted of 9 populations and 133 individuals. We also analyzed a dataset excluding $P$. tesselatus individuals from Morocco, which consisted of 8 populations and 127 individuals of $P$. spumarius. In order to compare morphological variation and genetic variation in P. spumarius, we used a dataset of the 32 individuals for which we had data for both morphometry and RAD-seq. We performed PCA for both types of data, as above, and we calculated Spearman correlations between the Principal Component scores obtained from both PCAs using R.

\section{Detection of selection - outlier analyses and environmental associations}

In order to detect loci with signs of selection for the P. spumarius RAD-seq dataset (without Morocco), two approaches were taken: one that detects outlier loci departing from expectation under neutral demographic models (Foll \& Gaggiotti, 2008; Vitalis et al., 2014), and another that 
335 detects loci associated with environmental variation between populations (Coop et al., 2010;

336 Gautier, 2015).

337

338 Outlier analyses were carried out using BAYESCAN v. 2.1 (Foll \& Gaggiotti, 2008) and

339 SELESTIM v1.1.4 (Vitalis et al., 2014). BAYESCAN uses a Bayesian approach to estimate the

340 posterior probability of two alternative models for each locus, with or without selection.

341 Posterior odds are then obtained and False Discovery Rate calculated to control for multiple

342 testing. The parameters of the chain and of the model were set to the default values. Outlier

343 SNPs were defined to be those with $q$-values lower than 5\%. SELESTIM v1.1.4 (Vitalis et al.,

344 2014) estimates the intensity of selection at each locus and the posterior distributions of the

345 locus-specific coefficients of selection are compared with a distribution derived from the

346 genome-wide effect of selection using Kullback-Leibler divergence (KLD). KLD is calibrated

347 with simulations from posterior predictive distribution based on observed data (Vitalis et al.,

348 2014). A total of 50 pilot runs of length 1000 were followed by a run of 1000000 with burnin of

349 10000. The criterion for a candidate SNP for selection was defined to be the $99 \%$ quantile of the 350 KLD distribution.

351

352 Environmental and geospatial variables used in the association analysis included 19 bioclimatic 353 variables, as well as longitude and latitude. Bioclimatic variables were mined from WorldClim 354 version 1.4 (release 3) (http://www.worldclim.org/) and the data was extracted for each location 355 using DIVA-GIS 7.5.0 (http://www.diva-gis.org). Associations between SNP allele frequency 356 differences and the environmental variables were assessed with BAYPASS v. 2.1 (Gautier, 357 2015), using the script Baypass_workflow.R

358 (https:/gitlab.com/StuntsPT/pyRona/blob/master/pyRona/R/Baypass workflow.R) as of 359 pyRONA v0.3.7 (Pina-Martins et al., 2019). Significant associations were assessed with Bayes 360 Factor (BF) obtained with the auxiliary covariate model, considering a threshold for BF of 15. 361 We did not exclude any variable at the start of the study based on their correlations, but we did 362 reassess correlation between significantly associated variables. Spearman correlations between 363 variables were calculated using $\mathrm{R}$. 
365 After finding the candidate SNPs for selection and environmental association, two datasets were 366 created: a "neutral" dataset, for which we excluded the candidate SNPs, and a "candidate"

367 dataset, that contained only the candidate SNPs. STRUCTURE analyses were also performed on 368 these two datasets.

369

370 RAD tags with candidate SNPs were queried against the available $P$. spumarius partial draft 371 genome and transcriptome (Rodrigues et al., 2016), using blastn with an e-value threshold of 1E372 30. We obtained a longer sequence (100 bp extended from each end of the RAD tag) from the 373 genome alignment, which was then queried against the NCBI nucleotide database (nr/nt) using 374 BLASTN version 2.9.0 (Altschul et al., 1997), setting a threshold e-value of 1E-5.

375

376 Scripts used in this analysis are available at

377 https://github.com/seabrasg/popgenom_Philaenus.git.

378

379

380

381

Results

382 Morphology of male aedeagus

383 The analysis of male genitalia revealed strong differentiation of the three Morocco samples, 384 which showed a characteristic P. tesselatus aedeagus, as originally described in Drosopoulos and 385 Quartau (2002): with the upper appendages longer and weakly curved, extending beyond the 386 lateral appendages and the lower appendages longer and more regularly curved than $P$. spumarius (Supplementary Figure S1). All the remaining samples showed P. spumarius-like aedeagi (Supplementary Figure S1). Morphometric analysis confirmed this distinction, with the segregation of Moroccan samples along the first component in the PCA (Figure 3A and 3B). The variables most associated with this distinction are the mean lengths of upper and of lower appendages of the aedeagus (PCA loadings in Supplementary Table S2a; boxplots in

392 Supplementary Figure S2). The longer appendages in P. tesselatus are expected to be related to 393 the longer body size in general in this species (Drosopoulos \& Quartau, 2002) but, when 
394 controlling for the total length of the aedeagus, the relative size of the lower appendages

395 remained larger in Moroccan samples (Supplementary Figure S2).

396

397 Within P. spumarius we also noted variation across samples, mainly due to the morphometric

398 variables of length and curvature of the upper appendages (Supplementary Figure S2; PCA

399 loadings in Supplementary Table S2b). In particular, there was some geographical structure, for

400 example UK and Finland lying on one extreme of PC2 and Greece lying on the other,

401 corresponding also to the extremes of latitude in this study. A less accentuated curvature and also

402 smaller length of the upper appendages in the Finnish and British than in the Greek samples may

403 be behind this differentiation (boxplots in Supplementary Figure S2).

404

405 Mitochondrial DNA

406 The fragment of COI spanned $540 \mathrm{bp}$ and was analyzed for 48 specimens, revealing 25

407 haplotypes, 21 of which had already been described in Rodrigues et al. (2014). The remaining

408 four (haplotypes UK15, UK18, GR18_13 and FIN9) differed from previously known haplotypes

409 by 1 or 2 substitutions (Supplementary Figure S3). Two of these new haplotypes (GR18_13 and

410 FIN9) lay in an intermediate position in the haplotype network between the previously defined

411 "North-Eastern" and "Western" haplogroups. In fact, the three haplogroups are not completely

412 distinct but we maintain their designation in order to more easily describe and visualize the

413 mitochondrial variation in relation to the RAD-seq variation: "Eastern-Mediterranean" (EM) in

414 red, "Western" (W) in green and "North-Eastern" (NE) in blue (Supplementary Figure S3). We

415 also attributed similar colors to the groups resulting from RAD-seq for ease of visualization (see

416 below Figure 6C).

417

418 All seven specimens from Morocco (MOR) sequenced for mtDNA either showed the most

419 common haplotype of the "W" haplogroup (H29) or a haplotype differing by only one

420 substitution (H28 and H37) (Supplementary Figure S3). All haplotypes from the Azores (AZO)

421 and continental Portugal (POR) belonged to "W". France (FRAN) haplotypes belonged in "W"

422 or in between "W" and "EM" (haplotype H49). Haplotypes from Greece (GRE) belonged to

423 "EM" or in between "W" and "NE" (haplotype GR18_13). Haplotypes from Turkey (TUR)

424 belonged to "NE". In Finland (FIN), there were haplotypes from "EM", "NE" and also one 
425 between "W" and "NE". The USA population comprised haplotypes from "NE" and the UK 426 population from "NE" and "W" (Supplementary Figure S3). The four new haplotypes were 427 submitted to GenBank under accession numbers MT025773-MT025776.

428

429

430

431

432

433

434

435

436

437

438

439

440

441

442

443

444

445

446

447

448

449

450

451

452

453

454

\section{RAD sequencing}

A total of 838730936 reads was obtained from the Illumina sequencing. The process_radtags step in STACKS retained 647870180 reads. This corresponds to an average of $3811001 \pm$ 3524799 (standard deviation) reads per individual. Thirty-seven individuals with lower numbers of reads ( $<500000$ reads) or large amounts of missing data $(>60 \%)$ were excluded from the analysis (Supplementary Table S1), leaving a total of 133 individuals, for which the number of reads ranged from 736248 to 23798148 (average $4507853 \pm 3668879$ sd). Raw reads after demultiplexing were deposited in SRA database with accession PRJNA606428. The population STACKS module, followed by filtering, produced 1,691 SNPs, with a mean coverage of 105.5 reads per locus per individual (Supplementary Figure S4) and mean percentage of missing data per individual of $12.3 \%$ (Supplementary Table S1). We applied relatively stringent filtering criteria to avoid having large amounts of missing data per individual resulting from the large genome size in this species (2.58 Gbases; Rodrigues et al., 2016). This has produced a relatively small number of SNPs but that have a good representation across individuals and that are expected to be scattered across the genome. Since the draft genome is still incomplete and very scattered we were not able to assess this distribution.

\section{Population structure}

Principal Component 1 in the PCA clusters Morocco individuals away from the others (Figure $3 \mathrm{C}$ and $\mathrm{D}$ ). When testing other assembly and filter parameters we obtained similar patterns in the groupings of samples (Supplementary Figure S5). Also, STRUCTURE analysis gave support to a genetic group solely comprising Moroccan samples (the best K according to Evanno et al. 2005 was 4; Figure 4). The average $\mathrm{F}_{\mathrm{ST}}$ of Morocco versus other populations was 0.4 , much higher than average $\mathrm{F}_{\mathrm{ST}}$ of other populations' comparisons (0.13) (Table 1). In all population-pairwise $\mathrm{F}_{\mathrm{ST}}$ calculations involving Morocco, there were a considerable number of SNPs that were fixed or nearly fixed for one allele in Morocco and for the other allele in all the other populations, as 
455 seen in the relatively high frequency of high $\mathrm{F}_{\mathrm{ST}}$ values on the histograms in all comparisons and 456 in the high correlations between $\mathrm{F}_{\mathrm{ST}}$ values among population pairs (Supplementary Figure S6a). 457 There was neither such a high number of fixed SNPs nor such high correlations between $\mathrm{F}_{\mathrm{ST}}$ 458 values when considering the other pairs of populations (Supplementary Figure S6b). Moroccan 459 samples are thus clearly differentiated, at the genome-wide markers, from the remaining eight 460 populations here analyzed in contrast with mtDNA results that showed no differentiation 461 between Morocco and the Iberian Peninsula (Supplementary Figure S3).

462

463 The relationship between geographical and genetic distances was significant when considering 464 European populations (excluding from the dataset USA, Azores and Morocco) (Mantel test, $465 \mathrm{z}=19.49793, \mathrm{p}=0.0177$; Figure 5). When considering the comparisons involving Morocco, a 466 positive correlation is seen between genetic and geographical distances, but mainly because of 467 the lower $F_{\text {ST }}$ value obtained between Morocco and Portugal $\left(F_{\text {ST }}=0.34\right)$, than between Morocco 468 and the other populations $\left(\mathrm{F}_{\mathrm{ST}}>0.4\right.$; Figure 5). This lower differentiation may be the result of 469 some level of admixture, which was detected in the STRUCTURE analysis, where all individuals 470 from the Portuguese population show a small contribution from the genetic group present in 471 Morocco (Figure 4).

472

473 Mean diversity (expected heterozygosity, $\mathrm{H}_{\mathrm{E}}$ ) ranged from 0.0373 (in Morocco) to 0.0808 (in 474 Greece) and mean observed heterozygosity $\left(\mathrm{H}_{\mathrm{O}}\right)$ from 0.0258 (in Morocco) to 0.0537 (UK). $\mathrm{H}_{\mathrm{O}}$ 475 values were generally lower than expected under Hardy-Weinberg equilibrium (HWE) in all 476 populations (average $\mathrm{F}_{\mathrm{IS}}$ of 0.346) (Table 1). For Morocco, interpretation of $\mathrm{H}_{\mathrm{E}}$ should be carried 477 out carefully, since individuals come from three different locations and thus are not necessarily 478 expected to be in HWE. Additionally, we found a positive and significant correlation between 479 observed heterozygosity and sequence read depth $\left(r_{S}=0.686, p=0.0412\right.$; Supplementary Figure 480 S7). This suggests that lower read depths may have led in some cases to allele dropout, 481 contributing towards false homozygotes. However, in the case of Morocco, the mean read depths 482 were not the lowest in this dataset, being similar to others (Supplementary Figure S4) and thus 483 this should not be the main factor contributing to the low observed heterozygosity. 
485 The dataset without Moroccan samples consisted of 127 individuals and 2083 SNPs. For this 486 dataset, PCA revealed two distinct clusters along PC1, generally separating Greece and Turkey 487 from the remaining populations (Figure 6A). The latter were separated along PC2 in three 488 groups, one including mainly Portugal and France, another including mainly Finland. A third 489 one, in between these two, including USA, UK and the Azores (Figure 6A). This structure had 490 already been detected in PC3 of the analysis of the dataset that included Morocco (Figure 3D). 491 For this dataset, when excluding the USA and the Azores populations, there was again 492 significant isolation-by-distance for the European populations (Mantel test, $\mathrm{z}=19.49793$, $493 \mathrm{p}=0.0229)$. However, there were a few individuals that were genetically more similar to 494 geographically more distant individuals, which is also seen in the STRUCTURE analysis (Figure 495 6). In Greece and Finland, there were no admixed individuals between the two main clusters 496 ("Eastern-Mediterranean" in red, and "North-Eastern" in blue) - they were either from one or the 497 other group, with a few exceptions (Figure 6B). An analysis of the Turkish population revealed 498 the presence of possibly admixed individuals from these two groups (with a smaller contribution 499 from the "North-Eastern" cluster). In the USA and UK populations, all individuals showed some 500 level of admixture between the "North-Eastern" (blue) and the "Western" (green) clusters. The 501 Azores allies a small contribution from the "Western" group to a major one belonging to the 502 "North-Eastern" group and one individual was admixed between "North-Eastern" and "Eastern503 Mediterranean" (also seen in PCA). The admixture in USA, UK and the Azores is also apparent 504 from their intermediate position between the Portugal+France group and the 505 Finland+Greece+Turkey group in the PCA (Figure 6A). The best $\mathrm{K}$ in the STRUCTURE 506 analysis, according to the method by Evanno et al. (2005), was 3.

507

508 The majority of specimens for which COI sequence was available, had a correspondence 509 between the mtDNA and the genomic cluster. However, there were some specimens showing a 510 mismatch consisting of a mtDNA haplotype belonging in a different genomic cluster (Figure 6B 511 and C; Supplementary Figure S3). For example, one individual from UK (UK6) bearing a 512 mtDNA haplotype (H24) belonging to "Western" haplogroup (green), turned up "North-Eastern" 513 (blue) in the genome analysis. Two individuals from France, bearing mtDNA H49 haplotype 514 (intermediate between "Western" and "Eastern-Mediterranean"), came up as differentiated at 515 genomic markers, one "Western" (green) and the other intermediate "Western" / "North- 
516 Eastern". In Greece and Finland, COI sequenced individuals show both a mtDNA and genomic 517 makeup belonging to either "Eastern-Mediterranean" or "North-Eastern", except two individuals 518 assessed as "North-Eastern" in genomic markers but with a mtDNA haplotype in intermediate 519 position in the network, between "Western" and "North-Eastern" haplogroups. The four 520 individuals from Turkey sequenced for COI belonged in "North-Eastern" haplotypes. While one 521 of them had full ancestry from "North-Eastern" group, the other three had their largest 522 proportion of ancestry from "Eastern-Mediterranean", based on the genome-wide markers. 523

524 For samples for which both morphometric and RAD-seq data was available $(\mathrm{N}=32)$, we 525 computed Principal Components Analysis (Supplementary Figure S8) and calculated the 526 correlation between PC1 and PC2 scores for both analyses. There was a significant correlation 527 between PC1 from morphometry and PC2 from RAD-seq $\left(r_{S}=0.63, p=1 E-04\right)$, while all the 528 remaining were low and non-significant $\left(\mathrm{r}_{\mathrm{S}}=-0.22, \mathrm{p}=0.2194\right.$ between PC1 from each; $\mathrm{r}_{\mathrm{S}}=0.1$, $529 \mathrm{p}=0.5927$ between PC2 from each; $\mathrm{r}_{\mathrm{S}}=0.29, \mathrm{p}=0.102$ between PC2 from morphometry and PC1 530 from RAD-seq).

531

532

533 Detection of selection - outlier analysis and environmental associations

534 Candidate SNPs for positive selection were identified by detection of highly differentiated 535 outliers: eight were detected by BAYESCAN (Supplementary Figure S9); and 25 by KLD 536 (quantile 99\% KLD 2.037087) in SELESTIM (Supplementary Figure S10; Supplementary Table 537 S3). Six outlier SNPs were common to both analyses. No outlier SNPs for balancing selection 538 were detected in the BAYESCAN analysis (Supplementary Figure S9).

539

540 The BAYPASS analysis detected 163 SNPs associated with environmental variables $(\mathrm{BF}>15)$

541 (Supplementary Table S3 and S4; Supplementary Figure S11), one of them common to the

542 candidate SNPs detected with Bayescan. Variables showing association were: Longitude,

543 Temperature Annual Range, Precipitation of Driest Quarter, Precipitation of Wettest Quarter,

544 Mean Temperature of Warmest Quarter, Mean Diurnal Range (Mean of monthly (max temp -

$545 \mathrm{~min}$ temp)). Spearman correlations between these 6 variables were generally low (absolute

546 values below 0.6 ), with only two values above 0.6 (Supplementary Table S4c). 
547

548 When excluding these candidate SNPs (188 in total) from the "full" dataset, creating a "neutral"

549 dataset, the main pattern of structuring was maintained, differing only in admixture proportions

550 at higher values of K (4 and 5) (PCA in Supplementary Figure S12 and STRUCTURE in

551 Supplementary Figure S13). When analysing the "candidates" dataset, the PCA showed a 552 separation that corresponded generally to longitude variation along PC1 and to latitude along

553 PC2 (Supplementary Figure S12). The STRUCTURE analysis, although artificial for the dataset 554 of loci under selection, revealed similar structuring when compared to the other datasets, but 555 with less admixture (Supplementary Figure S13). This is an expected outcome considering that

556 these candidate loci have similar allelic variation within each population and different allelic

557 variation between populations. The fact that there are still differentiated individuals within 558 populations in this dataset, consistently assigned to the same groups as in the other datasets, is a 559 reflection of the methods for detecting selection, based on population allelic variation.

560

561 Seventy-three candidate SNPs had hits (threshold e-value of 1E-30) with the draft genome of $P$. 562 spumarius and seven with the transcriptome (Rodrigues et al 2016). From these, nine had hits

563 (threshold evalue of 1E-5) with predicted genes in the NCBI nucleotide database (Supplementary 564 Table S3).

565

\section{Discussion}

567 RAD sequencing analysis revealed the genetic distinction of North-African relative to other 568 samples here analyzed, which matched the morphological differences at the male genitalia, 569 identifying these as Philaenus tesselatus. This genetic differentiation was however not detected 570 at the mitochondrial DNA level, since P. tesselatus and P. spumarius share mtDNA haplotypes, 571 as described in previous studies (Maryańska-Nadachowska et al., 2011; Rodrigues et al., 2014).

572 These results thus reinforce the importance of taking an integrative approach when studying the 573 taxonomy of a group of species, especially cryptic ones (Edwards \& Knowles, 2014; Dejaco et 574 al., 2016; Borges et al., 2017; Tonzo et al., 2019).

575

576 The fact that there are mitochondrial DNA haplotypes shared between $P$. tesselatus and $P$. 577 spumarius, while the nuclear genome is differentiated, may indicate selection on mtDNA 
578 following introgressive hybridization (Gompert et al., 2008). One possible mechanism for 579 selection on mtDNA described in several insects, is the occurrence of maternally inherited 580 endosymbionts, including Wolbachia, associated with certain haplotypes. These endosymbionts

581 are known to manipulate reproductive output, mainly through cytoplasmic incompatibility: no

582 viable offspring are produced when an infected male fertilizes an uninfected female, or a female 583 infected with a different strain (Werren, Baldo, \& Clark, 2008). Since both mitochondria and the 584 symbiont are maternally transmitted, haplotypes associated with the Wolbachia infection could 585 thus spread, hitchhiking through the population. Mitochondrial introgression between closely 586 related species caused by Wolbachia has been described in several species of Diptera and

587 Lepidoptera (Jiggins, 2003; Narita et al., 2006; Rousset \& Soulignac, 1995; Whitworth et al., 588 2007). In these cases, different species share the same mitochondrial haplotypes, making DNA 589 barcoding ineffective. Such a scenario would be interesting to investigate, as Wolbachia 590 infection has already been detected in P. spumarius across Europe and North America (Lis et al., 2015; Kapantaidaki et al., 2021; Wheeler et al., 2021, unpublished data).

592

593 The admixture from the Moroccan genetic group detected in all the individuals from the

594 Portuguese population (located in the Central-West part of the Iberian Peninsula) suggests some 595 level of recent or ongoing gene-flow between P. spumarius and P. tesselatus. Despite previous 596 doubts about the taxonomic status of these two taxa, our data point towards them being closely 597 related but independent gene-pools, probably early in the speciation "continuum" (Seehausen et 598 al., 2014). Both taxa co-occur in some locations in southern Iberian Peninsula (personal 599 observation by J. A. Quartau and A. C. Neto, based on identification by male aedeagus 600 morphology) and it will be important to study these sympatric areas. Genital traits are relevant 601 since they may contribute to reproductive isolation, either structural or sensory, if differences in 602 genital morphology between species prevent or reduce the success of copulation and 603 insemination (Masly, 2012). Structural isolation has been shown, for example, in the species pair 604 Drosophila yakuba Burla, 1954 and Drosophila santomea Lachaise \& Harry, 2000 (Kamimura $605 \&$ Mitsumoto, 2012), but in many species no convincing evidence for such isolation has been 606 found so far (Masly, 2012). Morphological variation in female genitalia, as well as behavioural 607 and physiological responses during mating may also aid in understanding potential mechanisms 608 of reproductive isolation, particularly in sympatry. We recognise that species identification based 
609 on male genitalia characteristics may be insufficient when there is intraspecific variation with

610 some overlap between species. Although our small P. tesselatus samples limit our understanding

611 of the range of its variation, genomic data allow higher resolution in detecting genetic

612 differentiation, but this is not enough to infer species status (Tonzo et al., 2019). A more

613 comprehensive study on morphology, mtDNA and genome-wide variation of a wider sample

614 from the Mediterranean region of both P. spumarius and $P$. tesselatus is required.

615

616 The morphometric geographical variation detected in $P$. spumarius showed some correlation

617 with genetic variation, although the nature of this association was not fully clear. Clinal

618 latitudinal variation, as well as elevation variation, in the shape of male genitalia had already

619 been described in European populations of P. spumarius (Wagner, 1955; 1959). Shorter and less

620 curved upper appendages were found in the north compared to the south, and in higher than in

621 lower altitudes in the same geographical regions (Wagner, 1955; 1959). RAD sequencing data

622 permitted detection of finer population genetic structure within $P$. spumarius than previously

623 known from mtDNA and a limited number of nuclear genes. Although there was a pattern of

624 isolation-by-distance in European populations, there were clear distinctions between groups in

625 the PCA and STRUCTURE analyses not related to geographical distance. The most likely K of

626 three in STRUCTURE corresponded loosely to the three mitochondrial haplogroups already

627 described in Rodrigues et al. (2014) and Maryańska-Nadachowska et al. (2011) but we detected

628 some degree of admixture along contact zones. We found admixed individuals in France, Turkey

629 and Finland, and several other individuals belonging to a different genetic group, with no

630 admixture. This may suggest recent migration or the maintenance of reproductive barriers. In

631 particular, there was almost no admixture between the "Eastern-Mediterranean" and the "North-

632 Eastern" groups. Maryańska-Nadachowska et al. (2011) described a contact zone in the

633 Carpathians between North-Eastern and South-Western haplogroups (this last group corresponds

634 to our "Western" and "Eastern-Mediterranean" together) and detected heteroplasmic

635 mitochondrial DNA, likely caused by paternal leakage from hybridization between members of

636 these two clades. Interestingly, Lis, Maryańska-Nadachowska and Kajtoch (2015) have found

637 different levels of Wolbachia infection between the different mitochondrial lineages of $P$.

638 spumarius. The North-Eastern clade showed a higher proportion of infected individuals than the

639 South-Western. In the Carpathian contact zone, infection was more prevalent in both groups, 
640 although they harboured different supergroups of Wolbachia. The authors suggest that there may

641 be limited gene-flow between genetically distinct populations through a mechanism of

642 cytoplasmic incompatibility. This could explain the low level of admixture detected in our study

643 between the two genetic groups. A genome-wide survey with a wider sampling of both genetic

644 groups will allow testing these hypotheses.

645

646 The intermediate position of UK, USA and Azores individuals in the PCA analysis, as well as 647 the admixture detected in STRUCTURE, suggest they are the result of mixed gene pools. It 648 further corroborates the mtDNA results of Rodrigues et al. (2014) which showed the occurrence 649 of mixed mitochondrial lineages in the UK and USA and that Azores and some USA samples 650 were genetically similar to those from the UK. Across North America, variation in the 651 morphology of male aedeagus in P. spumarius was reported by Hamilton (1979) and different

652 mtDNA haplogroups were detected by Rodrigues et al. (2014), leading to the suggestion of 653 multiple colonization events. The analyzed population from New Hampshire (USA) showed very 654 low genome-wide differentiation from the $\mathrm{UK}$ population (mean $\mathrm{F}_{\mathrm{ST}}=0.042$ ) compared to other 655 pairwise comparisons in this study, and also a large number of COI haplotypes belonging to the 656 "North-Eastern" haplogroup (5 in the 7 samples analyzed for mtDNA). This supports a likely 657 origin of the North American P. spumarius from Northern Europe, perhaps with multiple 658 colonization events and with large effective population sizes. In S. Miguel Island (Azores), only 659 two COI haplotypes, differing by one substitution, have been found so far (in 6 samples, 660 Rodrigues et al., 2014 and this study), which are closely related to the UK haplotypes from the 661 "Western" haplogroup. From the genomic results, this population was more differentiated from $662 \mathrm{UK}$ and USA (mean $\mathrm{F}_{\mathrm{ST}}=0.098$ between $\mathrm{AZO}$ and $\mathrm{UK}$, and mean $\mathrm{F}_{\mathrm{ST}}=0.078$ between $\mathrm{AZO}$ and 663 USA) than these two were from one another (mean $\mathrm{F}_{\mathrm{ST}}=0.042$ between UK and USA), showing 664 the lowest genetic diversity (expected heterozygosity) of all P. spumarius populations here 665 analyzed. These results suggest a likely origin of the Azores colonization from Northern Europe, 666 and that this colonization is likely to have involved a bottleneck event leading to reduced genetic 667 diversity. The low number of color morphs found in S. Miguel (Borges et al., 2018) in this

668 highly polymorphic species further supports this hypothesis, although selective processes may 669 also be involved. Expanding the sampling and analyzes will allow more precise determination of 
670 the origin, mode (whether or not mediated by man) and eventually the timing of these

671 transatlantic colonization events.

672

673 Population genomics approaches provide genome-wide information that is expected to reflect a

674 baseline of neutral processes and, at the same time, allow detection of loci with signatures of 675 selection, deviating from this baseline (Hohenlohe, Phillips, \& Cresko, 2010). We focused on 676 detecting local adaptation, by finding those loci that are more differentiated ( $\left.\mathrm{F}_{\mathrm{ST}}\right)$ between 677 populations than expected from the neutral background, and also by finding loci that have allelic 678 variation correlated with environmental variation. When discarding such candidate loci for 679 selection from our dataset, the population structure patterns remained very similar to the neutral 680 dataset, which means that these $9 \%$ of loci are not affecting the genome-wide neutral pattern of 681 population structure. Despite the usefulness of RAD sequencing for detection of selection in

682

683

684

685

686

687

688

689

690

691

692

693

694

695

696

697

698

699

700

natural populations (Catchen et al., 2017), this analysis is limited by the number of SNPs analyzed and also by the fact that RAD tags are usually distributed non-uniformly across the genome (Lowry et al., 2016). The large genome size of $P$. spumarius makes it more difficult to have a good genomic representation with these scattered markers. Also, genetic signatures of selection in individual loci can be weak and not easily detected in cases of soft selective sweeps (adaptation from standing genetic variation), epistatic interactions among loci or genotype-byenvironment interactions (Hohenlohe et al., 2010). Whole-genome analyses, by analysing patterns of diversity, differentiation and linkage disequilibrium along the genome, will be essential to better understand the evolutionary forces of selection and recombination shaping genomic variation (Ellegren, 2014). The fact that we did not detect loci under balancing selection in the BAYESCAN analysis may also be related to low marker density. P. spumarius is particularly known for its balanced polymorphism for dorsal color forms and the assessment of population variation in the color-associated loci (Rodrigues et al., 2016) remains to be done.

In the environmental association analysis, the associated variables were primarily longitude and those related to the extreme values and range variation in temperature and precipitation. This analysis is tentative, since we have a low number of populations from a wide geographic range. The low number of hits of the candidate loci with the $P$. spumarius transcriptome may indicate their location was mostly in non-coding regions, while the low number of hits with the partial

PeerJ reviewing PDF | (2020:09:53180:2:0:NEW 14 Apr 2021) 
701 genome denotes its incompleteness (Rodrigues et al., 2016). A more complete draft genome is

702

703

704

705

706

707

708

709

710

711

712

713

714

715

716

717

718

719

720

721

722

723

724

725

726

727

728

729

730

now available (Biello et al., 2020), and new genomic and transcriptomic resources will be soon generated for P. spumarius which will provide important tools to further explore the molecular basis of adaptation in this species.

Understanding species divergence and the population genetic structure of $P$. spumarius and related species of the genus Philaenus is relevant to the management of the eventual progression of the plant pathogenic bacterium $X$. fastidiosa, since their dispersal patterns might aid or constrain disease transmission. Also, the ecological characteristics of different taxa or local populations may be different, for example in host plant preference, ease of acquisition of $X$. fastidiosa or transmission efficiency. Understanding the specific ecology of the vectors has been shown to be crucial in the management of $X$. fastidiosa diseases in America (Redak et al., 2004). Integrating this information is important for epidemiological models of $X$. fastidiosa in Europe and other Mediterranean countries. The risk of $X$. fastidiosa transmission and disease progression is generally expected to be related to long-range human-assisted movements of infected plants and with shorter-range natural dispersal by vectors (EFSA et al., 2019). Genetic studies of $P$. spumarius have shown that it does not constitute a panmictic population and geographical distance is not the only factor restricting gene flow. Other factors have to be taken into account, including habitat fragmentation, barriers to gene exchange such as endosymbionts or behavioural differences, rapid climate changes that may cause major shifts in distribution ranges, as well as unpredictable adaptive responses (Kellermann \& Van Heerwaarden, 2019). Even without detectable gene flow, adults of $P$. spumarius may be able to migrate occasionally, or consistently but without reproductive outcome, and spread the bacterium. More ecological studies on the abundance and distribution of this insect vector through the seasons and across years are needed to understand the dispersal patterns across geographical regions and the potential for disease spread. It will be important to understand the dispersal patterns from South Italy, a potential source of contamination by $X$. fastidiosa and particularly its subspecies pauca, which includes the strain associated with OQDS. This is especially true as previous work detected haplotypes from distinct haplogroups in Italy. For example, Rodrigues et al. (2014) detected both "EasternMediterranean" and "Western" haplogroups in North and Central Italy, as well as in Sicily, 
731 unveiling the pivotal role of that region in the dispersal patterns of $P$. spumarius among the

732 Mediterranean peninsulas.

733.

734

735 Conclusions

736 In this study, morphological and genomic analysis allowed a more detailed view of the

737 divergence between $P$. spumarius and $P$. tesselatus, as well as of the population structure and

738 adaptation in P. spumarius. We found genome-wide divergence between these two species,

739 despite the lack of mitochondrial DNA differentiation between them. The population genomics

740 approach taken here showed admixture but also co-occurrence of non-admixed individuals in

741 contact zones of diverging mitochondrial lineages of $P$. spumarius. The potential role of

742 Wolbachia in shaping these patterns of divergence and introgression should be further explored.

743

744 The findings on species divergence and population structure described here point to the need for

745 elucidating the dispersal and ecological requirements of the different taxa and local populations

746 of these vectors for a better management of $X$. fastidiosa progression.

747

748

749

750

751 Acknowledgements

752 We thank Carla Pereira, Carla Rego, Rui Nunes and Luis Ferreira for help in field-work; Karim

753 Gharbi and Mark Blaxter for help with the RAD sequencing; Vera Nunes and Juan Farinas for

754 help in the laboratory; the Faculty of Sciences of the University of Lisbon's Microscopy Facility,

755 a node of the Portuguese Platform for Bioimaging, reference PPBI-POCI-01-0145-FEDER-

756 022122, where images from insect specimens were acquired. We thank Robin Bagley and two

757 anonymous reviewers for important contributions to improve the manuscript.

758

759 
763 References

764 Almeida, R. P. P., De La Fuente, L., Koebnik, R., Lopes, J. R. S., Parnell, S., \& Scherm, H. (2019).

765 Addressing the New Global Threat of Xylella fastidiosa. Phytopathology, 109, 172-174.

766 https://doi.org/10.1094/PHYTO-12-18-0488-FI

767

768 Altschul, S. F., Madden, T. L., Schäffer, A. A., Zhang, J., Zhang, Z., Miller, W., \& Lipman, D. J. 769 (1997). Gapped BLAST and PSI-BLAST: a new generation of protein database search programs. 770 Nucleic Acids Research, 25, 3389-3402. doi: 10.1093/nar/25.17.3389.

771

772 Andrews, K. R., Good, J. M., Miller, M. R., Luikart, G., \& Hohenlohe, P. A. (2016). Harnessing 773 the power of RADseq for ecological and evolutionary genomics. Nature Reviews Genetics, 774 17(2), 81-92. doi: 10.1038/nrg.2015.28.

775

776 Baldi, P., \& La Porta, N. (2017). Xylella fastidiosa: Host Range and Advance in Molecular 777 Identification Techniques. Frontiers in Plant Science, 8, 944. doi: 10.3389/fpls.2017.00944

778

779 Bahrndorff, S., Ruiz-González, A., Jonge, N. De, Nielsen, J. L., Skovgård, H., \& Pertoldi, C.

780 (2020). Integrated genome-wide investigations of the housefly, a global vector of diseases reveal 781 unique dispersal patterns and bacterial communities across farms. BMC Genomics, 21, 66. doi. 782 10.1186/s12864-020-6445-z.

783

784 Baird, N. A., Etter, P. D., Atwood, T. S., Currey, M. C., Shiver, A. L., Lewis, Z. A., Selker, E. 785 U., Cresko, W. A., \& Johnson, E. A. (2008). Rapid SNP discovery and genetic mapping using 786 sequenced RAD markers. PloS One, 3(10), e3376. doi: 10.1371/journal.pone.0003376. 787

788 Bandelt, H. J., Forster, P., \& Rohl, A. (1999). Median-joining networks for inferring intraspecific 789 phylogenies. Molecular Biology and Evolution, 16(1), 37-48. doi:

790 10.1093/oxfordjournals.molbev.a026036. 
791

792 Beal, D. J., Cooper, M., Daugherty, M. P., Purcell, A. H., \& Almeida, R. P. P. (2021). Seasonal 793 abundance and infectivity of Philaenus spumarius (Hemiptera: Aphrophoridae), a vector of 794 Xylella fastidiosa in California vineyards. Environmental Entomology 10 pp. nvaa178, doi: $795 \quad \underline{10.1093 / \text { ee/nvaa178 }}$

796

797

798

Biello, R., Mathers, T. C., Mugford, S. T., Liu, Q., Rodrigues, A. S. B., Neto, A. C., Rebelo, M. 799 T., Paulo, O. S., Seabra, S. G., \& Hogenhout, S. A. (2020). Draft genome assembly version 1 of 800 the meadow spittlebug Philaenus spumarius (Linnaeus, 1758) (Hemiptera, Aphrophoridae)

801 (Version version 1) [Data set]. Zenodo. doi: 10.5281/zenodo.3368385.

802

803 Borges, P. A. V., Amorim, I. R., Terzopoulou, S., Rigal, F., Emerson, B., \& Serrano, A. R. M. 804 (2017). Cryptic diversity in Azorean beetle genus Tarphius Erichson, 1845 (Coleoptera:

805 Zopheridae): An integrative taxonomic approach with description of four new species. Zootaxa, 806 4236, 401-449. doi: 10.11646/zootaxa.4236.3.1.

807

808

Borges, P. A. V, Rodrigues, A. S. B., Silva, S. E., Seabra, S. G., Paulo, O. S., \& Quartau, J. A. 809 (2018). New data on polymorphism of the meadow spittlebug Philaenus spumarius (L.)

810 (Hemiptera: Aphrophoridae) from the island of São Miguel (Azores), Zootaxa, 4369(1), 144811 150. doi: 10.11646/zootaxa.4369.1.9.

812

813 Busvine, J. R. (1980). Cryptic species of insect disease vectors and their importance. Endeavour, 814 4(3), 108-112. DOI: 10.1016/0160-9327(80)90057-5.

815

816 Catchen, J., Hohenlohe, P. A., Bassham, S., Amores, A., \& Cresko, W. A. (2013). Stacks: an 817 analysis tool set for population genomics. Molecular Ecology, 22(11), 3124-3140. doi:

$81810.1111 / \mathrm{mec} .12354$.

819

820 Catchen, J. M., Hohenlohe, P. A., Bernatchez, L., Funk, W. C., Andrews, K. R., \& Allendorf, F. 821 W. (2017). Unbroken : RADseq remains a powerful tool for understanding the genetics of 
822 adaptation in natural populations. Molecular Ecology Resources, 17, 362-365. doi:

$823 \quad \underline{10.1111 / 1755-0998.12669 .}$

824

825 Coop, G., Witonsky, D., Di Rienzo, A., \& Pritchard, J. K. (2010). Using environmental

826 correlations to identify loci underlying local adaptation. Genetics, 185(4), 1411-1423. doi:

827 10.1534/genetics.110.114819.

828

829 Cornara, D., Saponari, M., Zeilinger, A. R., Stradis, A. De, Boscia, D., Loconsole, G., Bosco, D., 830 Martelli, G. P., Almeida, R. P. P., \& Porcelli, F. (2017). Spittlebugs as vectors of Xylella

831 fastidiosa in olive orchards in Italy. Journal of Pest Science, 90(2), 521-530. doi:

832 10.1007/s10340-016-0793-0.

833

834 Cornara, D., Morente, M., Markheiser, A., Bodino, N., Tsai, C.-W., Fereres, A., Redak, R. A.,

835 Perring, T. M., \& Lopes, J. R. S. (2019). An overview on the worldwide vectors of Xylella 836 fastidiosa. Entomologia Generalis, 39(3-4), 157-181. doi: 10.1127/entomologia/2019/0811

837

838 Danecek, P., Auton, A., Abecasis, G., Albers, C. A., Banks, E., DePristo, M. A., Handsaker, R. 839 E., Lunter, G., Marth, G, T., Sherry, S. T., McVean, G., Durbin, R., \& Group, 1000 Genomes 840 Project Analysis. (2011). The variant call format and VCFtools. Bioinformatics, 27(15), 2156841 2158. doi: 10.1093/bioinformatics/btr330.

842

843 Dejaco, T., Gassner, M., Arthofer, W., Schlick-Steiner, B. C., \& Steiner, F. M. (2016).

844 Taxonomist' s nightmare ... Evolutionist' s delight: an integrative approach resolves species

845 limits in jumping bristletails despite widespread hybridization and parthenogenesis. Systematic 846 Biology, 65(6), 947-974. doi: 10.1093/sysbio/syw003.

847

848 Dohm, J. C., Lottaz, C., Borodina, T., \& Himmelbauer, H. (2008). Substantial biases in ultra849 short read data sets from high-throughput DNA sequencing. Nucleic Acids Research, 36, e105. 850 doi: 10.1093/nar/gkn425. 
852 Drosopoulos, S. (2003). New data on the nature and origin of colour polymorphism in the 853 spittlebug genus Philaenus (Hemiptera: Aphorophoridae). Annales de la Société Entomologique 854 de France, 39(1), 31-42. doi: 10.1080/00379271.2003.10697360.

855

856 Drosopoulos, S., \& Quartau, J.A. (2002). The spittlebug Philaenus tesselatus Melichar, 1899

857 (Hemiptera, Auchenorrhyncha, Cercopidae) is a distinct species. Zootaxa 68: 1-8. doi:

858 10.11646/zootaxa.68.1.1.

859

860 Earl, D. A., \& vonHoldt, B. M. (2012). STRUCTURE HARVESTER: a website and program for 861 visualizing STRUCTURE output and implementing the Evanno method. Conservation Genetics 862 Resources, 4(2), 359-361. doi: 10.1007/s12686-011-9548-7.

863

864 Edwards, D. L., \& Knowles, L. L. (2014). Species detection and individual assignment in species 865 delimitation: can integrative data increase efficacy? Proceedings of the Royal Society B:

866 Biological Sciences, 281, 20132765. doi: 10.1098/rspb.2013.2765.

867

868 EFSA Panel on Plant Health (PLH). (2015). Scientific Opinion on the risks to plant health posed 869 by Xylella fastidiosa in the EU territory, with the identification and evaluation of risk reduction 870 options. EFSA Journal, 13(1), 3989. doi: 10.2903/j.efsa.2015.3989.

871

872 EFSA (European Food Safety Authority), Vos, S., Camilleri, M., Diakaki, M., Lázaro, E., 873 Parnell, S., ... Vicent, A. (2019). Pest survey card on Xylella fastidiosa. EFSA supporting 874 publication (Vol. 2019:EN-16). doi: 10.2903/sp.efsa.2019.EN-1667.

875

876 Ellegren, H. (2014). Genome sequencing and population genomics in non-model organisms. 877 Trends in Ecology \& Evolution, 29(1), 51-63. doi: 10.1016/j.tree.2013.09.008.

878

879 Etter, P. D., Bassham, S., Hohenlohe, P.A., Johnson, E., \& Cresko, W.A, (2011) SNP discovery 880 and genotyping for evolutionary genetics using RAD sequencing. In: Molecular Methods for 881 Evolutionary Genetics (eds Orgogozo V, Rockman MV), pp. 157-178. Humana Press, New 882 York. doi: 10.1007/978-1-61779-228-1 9. 
883

884 Evanno, G., Regnaut, S., \& Goudet, J. (2005). Detecting the number of clusters of individuals 885 using the software STRUCTURE: a simulation study. Molecular Ecology, 14, 2611-2620. doi: $88610.1111 /$ j.1365-294X.2005.02553.x.

887

888 Falush, D., Stephens, M., \& Pritchard, J. K. (2003). Inference of population structure using 889 multilocus genotype data: linked loci and correlated allele frequencies. Genetics, 164, 15678901587.

891

892 Foll, M., \& Gaggiotti, O. (2008). A genome-scan method to identify selected loci appropriate for 893 both dominant and codominant markers: a bayesian perspective. Genetics, 180, 977-993. doi:

894 10.1534/genetics.108.092221.

895

896 Gautier, M. (2015). Genome-wide scan for adaptive divergence and association with population897 specific covariates. Genetics, 201(4), 1555-1579. doi: 10.1534/genetics.115.181453. 898

899 Gompert, Z., Forister, M. L., Fordyce, J. A., \& Nice, C. C. (2008). Widespread mito-nuclear 900 discordance with evidence for introgressive hybridization and selective sweeps in Lycaeides. 901 Molecular Ecology, 17, 5231-5244. doi: 10.1111/j.1365-294X.2008.03988.x. 902

903 Halkka, O., \& Halkka, L. (1990). Population genetics of the polymorphic meadow spittlebug, 904 Philaenus spumarius (L.). Evolutionary Biology (USA), 24, 149-191.

905

906 Halkka, O., Raatikainen, M., Vasarainen, A., \& Heinonen, L. (1967). Ecology and ecological 907 genetics of Philaenus spumarius (L.) (Homoptera). Annales Zoologici Fennici, 4, 1-18.

908

909 Hall, T.A. (1999). BioEdit: A User-Friendly Biological Sequence Alignment Editor and Analysis 910 Program for Windows 95/98/NT. Nucleic Acids Symposium Series, 41, 95-98. 
912 Hamilton, K. G. A. (1979). Synopsis of North American Philaenini (Rhynchota: Homoptera:

913 Cercopidae) with a new genus and four new species. The Canadian Entomologist, 111, 127-141.

914

915 Hendry, A. P., Bolnick, D. I., Berner, D., \& Peichel, C. L. (2009) Along the speciation

916 continuum in sticklebacks. Journal of Fish Biology, 75, 2000-2036. doi: 10.1111/j.1095-

917 8649.2009.02419.x.

918

919 Hohenlohe, P. A., Phillips, P. C., \& Cresko, W. A. (2010). Using population genomics to detect 920 selection in natural populations: key concepts and methodological considerations. International 921 Journal of Plant Science, 171(9), 1059-1071. doi: 10.1086/656306.

922

923 Jakobsson, M., \& Rosenberg, N. A. (2007). CLUMPP: a cluster matching and permutation 924 program for dealing with label switching and multimodality in analysis of population structure.

925 Bioinformatics, 23(14), 1801-1806. doi: 10.1093/bioinformatics/btm233.

926

927 Jiggins, F. M. (2003). Male-killing Wolbachia and mitochondrial DNA : selective sweeps, hybrid 928 introgression and parasite population dynamics. Genetics, 164, 5-12.

929

930 Kamimura, Y., \& Mitsumoto, H. (2012). Lock-and-key structural isolation between sibling 931 Drosophila species. Entomological Science, 15, 197-201. doi: 10.1111/j.1479-

932 8298.2011.00490.x.

933

934 Kapantaidaki, D. E., Antonatos, S., Evangelou, V., Papachristos, D. P., \& Milonas, P. (2021). 935 Genetic and endosymbiotic diversity of Greek populations of Philaenus spumarius, Philaenus 936 signatus and Neophilaenus campestris, vectors of Xylella fastidiosa. Scientific Reports, 11(1), 937 3752. doi: 10.1038/s41598-021-83109-z.

938

939 Karban, R., \& Huntzinger, M. (2018). Decline of meadow spittlebugs, a previously abundant 940 insect, along the California coast. Ecology, 99, 2614-2616. doi: 10.1002/ecy.2456. 
942 Karban, R., \& Strauss, S. (2004). Physiological tolerance, climate change, and a northward range 943 shift in the spittlebug, Philaenus spumarius. Ecological Entomology, 29, 251-254. doi:

$944 \quad 10.1111 / \mathrm{j} .1365-2311.2004 .00576 . x$.

945

946 Kellermann, V., \& Van Heerwaarden, B. (2019). Terrestrial insects and climate change: adaptive 947 responses in key traits. Physiological Entomology, 44, 99-115. doi: 10.1111/phen.12282.

948

949 Leigh, J. W., \& Bryant, D. (2015). PopART: Full-feature software for haplotype network 950 construction. Methods in Ecology and Evolution, 6(9), 1110-1116. doi: 10.1111/2041$951 \underline{210 X .12410 .}$.

952

953 León, J., Jones, W. \& Morgan, D. (2004). Population genetic structure of Homalodisca 954 coagulata (Homoptera: Cicadellidae), the vector of the bacterium Xylella fastidiosa causing 955 Pierce's disease in grapevines. Annals of the Entomological Society of America, 97(4), 809-818. 956 doi: 10.1603/0013-8746(2004)097[0809:PGSOHC]2.0.CO;2.

957

958 Linck, E., \& Battey, C. J. (2019). Minor allele frequency thresholds strongly affect population 959 structure inference with genomic data sets, Molecular Ecology Resources, 19(3), 639-647. doi: $96010.1111 / 1755-0998.12995$.

961

962 Lis, A., Maryańska-Nadachowska, A., \& Kajtoch, Ł. (2015). Relations of Wolbachia infection 963 with phylogeography of Philaenus spumarius (Hemiptera: Aphrophoridae) populations within 964 and beyond the Carpathian contact zone. Microbial Ecology, 70(2), 509-521. doi:

$96510.1007 / \mathrm{s} 00248-015-0570-2$.

966

967 Lis, A., Maryańska-Nadachowska, A., Lachowska-Cierlik, D., \& Kajtoch, L. (2014). The 968 secondary contact zone of phylogenetic lineages of the Philaenus spumarius (Hemiptera: 969 Aphrophoridae): an example of incomplete allopatric speciation. Journal of Insect Science, 14, 970 227. doi: 10.1093/jisesa/ieu089. 
972 Lischer, H. E. L., \& Excoffier, L. (2012) PGDSpider: An automated data conversion tool for 973 connecting population genetics and genomics programs. Bioinformatics, 28, 298-299. doi:

974 10.1093/bioinformatics/btr642.

975

976 Lowry, D. B., Hoban, S., Kelley, J. L., Lotterhos, K. E., Reed, L. K., Antolin, M. F., \& Storfer, 977 A. (2016). Breaking RAD: An evaluation of the utility of restriction site associated DNA 978 sequencing for genome scans of adaptation. Molecular Ecology Resources, 17, 142-152. doi: $97910.1111 / 1755-0998.12596$

980

981

Malinsky, M., Challis, R. J., Tyers, A. M., Schiffels, S., Terai, Y., Ngatunga, B. P., Miska, E. A.,

982 Durbin, R., Genner, M. J., \& Turner, G. F. (2015). Genomic islands of speciation separate cichlid 983 ecomorphs in an East African crater lake. Science (New York, N.Y.), 350(6267), 1493-1498. doi:

984 10.1126/science.aac9927

985

986

987

Maryańska-Nadachowska, A., Drosopoulos, S., Lachowska, D., Kajtoch, L., \& Kuznetsova, V.

988

G. (2010). Molecular phylogeny of the Mediterranean species of Philaenus (Hemiptera:

989

Auchenorrhyncha: Aphrophoridae) using mitochondrial and nuclear DNA sequences. Systematic

990

Entomology, 35, 318-328. doi: 10.1111/j.1365-3113.2009.00510.x.

991

992

Maryańska-Nadachowska, A., Kajtoch, Ł., \& Lachowska, D. (2011). Genetic diversity of

993

Philaenus spumarius and P. tesselatus (Hemiptera, Aphrophoridae): implications for evolution

994

and taxonomy. Systematic Entomology, 37(1), 55-64. doi: 10.1111/j.1365-3113.2011.00592.x.

995

996

Masly, J. P. (2012). 170 Years of "Lock-and-Key": genital morphology and reproductive

997 isolation. International Journal of Evolutionary Biology, 2012, 247352. doi:

998 $10.1155 / 2012 / 247352$.

999

1000 Nadeau, N. J., Whibley, A., Jones, R. T., Davey, J. W., Dasmahapatra, K. K., Baxter, S. W., 1001 Quail, M. A., Joron, M., ffrench-Constant, R. H., Blaxter, M. L., Mallet, J., \& Jiggins, C. D. 1002 (2012). Genomic islands of divergence in hybridizing Heliconius butterflies identified by large- 
1003 scale targeted sequencing. Philosophical Transactions of the Royal Society B: Biological 1004 Sciences, 367, 343-353. doi: 10.1098/rstb.2011.0198.

1005

1006 Narita, S., Nomura, M., Kato, Y., \& Fukatsu, T. (2006). Genetic structure of sibling butterfly 1007 species affected by Wolbachia infection sweep : evolutionary and biogeographical implications. 1008 Molecular Ecology, 15, 1095-1108. doi: 10.1111/j.1365-294X.2006.02857.x. 1009

1010

1011 1012

1013

1014 1015

1016

1017 1018

1019

1020

1021

1022

1023

1024

1025

1026

1027

1028

1029

1030

1031

1032

1033

1034

Nast, J. (1972). Palaearctic Auchenorrhyncha (Homoptera): An Annotated Check List. Institute of Zoology, Polish Academy of Sciences, Warsaw: Polish Scientific Publisher, 550 pp.

Nosil, P. (2012). Ecological Speciation. Oxford Series in Ecology and Evolution. 300 pp. New York: Oxford University Press. doi: 10.1093/acprof:osob1/9780199587100.001.0001.

Novembre, J., \& Stephens, M. (2008). Interpreting principal component analyses of spatial population genetic variation. Nature Genetics, 40(5), 646-649. doi: 10.1038/ng.139.

Peccoud, J., Ollivier, A., Plantegenest, M., \& Simon, J.-C. (2009). A continuum of genetic divergence from sympatric host races to species in the pea aphid complex. Proceedings of the National Academy of Sciences of the United States of America, 106(18), 7495-7500. doi: 10.1073/pnas.0811117106.

Pélissié, B., Crossley, M. S., Cohen, Z. P., \& Schoville, S. D. (2018). Rapid evolution in insect pests: the importance of space and time in population genomics studies Current Opinion in Insect Science, 26, 8-16. doi: 10.1016/j.cois.2017.12.008.

Pina-Martins, F., Silva, D. N., Fino, J., \& Paulo, O. S. (2017). Structure_threader: An improved method for automation and parallelization of programs structure, fastStructure and MavericK on multicore CPU systems. Molecular Ecology Resources, 17(6), e268-e274. doi: 10.1111/17550998.12702.

Pritchard, J. K., Stephens, M., \& Donnelly, P. (2000). Inference of population structure using multilocus genotype data. Genetics, 155, 945-959. 
1036 R Core Team (2017). R: A language and environment for statistical computing. R Foundation for 1037 Statistical Computing, Vienna, Austria. Available at: https://www.R-project.org/.

1038

1039 Redak, R. A., Purcell, A. H., Blua, M. J., Mizell, R. F., \& Andersen, P. C. (2004). The biology of 1040 xylem fluid-feeding insect vectors of Xylella fastidiosa and their relation to disease

1041 epidemiology. Annual Review of Entomology, 49, 243-270. doi:

1042 10.1146/annurev.ento.49.061802.123403.

1043

1044 Renaut, S., Maillet, N., Normandeau, E., Sauvage, C., Derome, N., Rogers, S. M., \& Bernatchez, 1045 L. (2012). Genome-wide patterns of divergence during speciation: the lake whitefish case study. 1046 Philosophical Transactions of the Royal Society B: Biological Sciences, 367, 354-363. doi:

1047 10.1098/rstb.2011.0197.

1048

1049 Riesch, R., Muschick, M., Villoutreix, R., Comeault, A. A., Farkas, T. E., Lucek, K., Hellen, E., 1050 Soria-Carrasco, V., Dennis, S. R., de Carvalho, C. F., Safran, R. J., Sandoval, C. P., Feder, J., 1051 Gries, R., Crespi, B.J., Gries, G., Gompert, Z., \& Nosil, P. (2017). Transitions between phases of 1052 genomic differentiation during stick-insect speciation. Nature Ecology \& Evolution, 1, 0082. doi: 1053 10.1038/s41559-017-0082.

1054

1055

Rodrigues, A. S. B., Silva, S. E., Marabuto, E., Silva, D. N., Wilson, M. R., Thompson, V., 1056 Yurtsever, S., Halkka, A., Borges, P. A. V., Quartau, J. A., Paulo, O. S., \& Seabra, S. G. (2014). New mitochondrial and nuclear evidences support recent demographic expansion and an atypical phylogeographic pattern in the spittlebug Philaenus spumarius (Hemiptera, Aphrophoridae). PLoS ONE, 9(6), e98375. doi: 10.1371/journal.pone.0098375.

1060

Rodrigues, A. S. B., Silva, S. E., Pina-Martins, F., Loureiro, J., Castro, M., Gharbi, K., Johnson, 1062 K. P., Dietricht, C. H., Borges, P. A. V., Quartau, J. A., Jiggins, C. D., Paulo, O. S., \& Seabra, S. G. (2016). Assessing genotype-phenotype associations in three dorsal colour morphs in the meadow spittlebug Philaenus spumarius (L.) (Hemiptera: Aphrophoridae) using genomic and 1065 transcriptomic resources. BMC Genetics, 17(1), 144. doi: 10.1186/s12863-016-0455-5. 
1066

1067 Rousset, F. (1997). Genetic differentiation and estimation of gene flow from F-Statistics under 1068 isolation by distance. Genetics, 145, 1219-1228.

1069

1070 Rousset, F., \& Solignac, M. (1995). Evolution of single and double Wolbachia symbioses during 1071 speciation in the Drosophila simulans complex. Proceedings of the National Academy of

1072 Sciences of the United States of America, 92, 6389-6393. doi:10.1073/pnas.92.14.6389.

1073

1074 Saponari, M., Loconsole, G., Cornara, D., Yokomi, R. K., Stradis, A. D. E., Boscia, D., Bosco, 1075 D., Martelli, G. P., Krugner, R., \& Porcelli, F. (2014). Infectivity and transmission of Xylella 1076 fastidiosa by Philaenus spumarius (Hemiptera: Aphrophoridae) in Apulia, Italy. Journal of 1077 Economic Entomology, 107(4), 1-4. doi: 10.1603/ec14142.

1078

1079 Seehausen, O., Butlin, R. K., Keller, I., Wagner, C. E., Boughman, J. W., Hohenlohe, P. A., ... 1080 Widmer, A. (2014). Genomics and the origin of species. Nature Reviews Genetics, 15(3), 1761081 192. doi: $10.1038 / \operatorname{mrg} 3644$.

1082

1083 Sicard, A., Zeilinger, A. R., Vanhove, M., Schartel, T. E., Beal, D. J., Daugherty, M. P., \& 1084 Almeida, R. P. P. (2018). Xylella fastidiosa: insights into an emerging plant pathogen. Annual 1085 Review of Phytopathology, 56, 181-202. doi: 10.1146/annurev-phyto-080417-045849.

1086

1087 Simon, C., Frati, F., Beckenbach, A., Crespi, B., Liu, H., \& Flook, P. (1994). Evolution, 1088 weighting, and phylogenetic utility of mitochondrial gene sequences and a compilation of 1089 conserved polymerase chain reaction primers. Annals of the Entomological Society of America, 1090 87, 651-701. doi: 10.1093/aesa/87.6.651.

1091

1092 Smadja, C. M., \& Butlin, R. K. (2011). A framework for comparing processes of speciation in 1093 the presence of gene flow. Molecular Ecology, 20, 5123-5140. doi: 10.1111/j.13651094 294X.2011.05350.x. 
1096 Smith P. T. (2005). Mitochondrial DNA variation among populations of the glassy-winged

1097 sharpshooter, Homalodisca coagulata. Journal of insect science (Online), 5, 41. doi:

$109810.1093 / \mathrm{jis} / 5.1 .41$

1099

1100 Sousa, V., \& Hey, J. (2013). Understanding the origin of species with genome-scale data:

1101 modelling gene flow. Nature Reviews. Genetics, 14(6), 404-14. doi: 10.1038/nrg3446.

1102

1103 Thompson, J. D., Higgins, D. G., Gibson, T. J. (1994). CLUSTAL W: improving the sensitivity

1104 of progressive multiple sequence alignment through sequence weighting, position-specific gap

1105 penalties and weight matrix choice. Nucleic Acids Research, 22, 4673-4680. doi:

1106 10.1093/nar/22.22.4673.

1107

1108 Tonzo, V., Papadopoulou, A., \& Ortego, J. (2019). Genomic data reveal deep genetic structure

1109 but no support for current taxonomic designation in a grasshopper species complex. Molecular

1110 Ecology, 28(17), 3869-3886. doi: 10.1111/mec.15189.

1111

1112 Turner, T. L., Hahn, M. W., \& Nuzhdin, S. V. (2005). Genomic islands of speciation in

1113 Anopheles gambiae. PLoS Biology, 3(9), e285. doi: 10.1371/journal.pbio.0030285.

1114

1115 Vijay, N., Bossu, C. M., Poelstra, J. W., Weissensteiner, M. H., Suh, A., Kryukov, A. P., \&

1116 Wolf, J. B. W. (2016). Evolution of heterogeneous genome differentiation across multiple

1117 contact zones in a crow species complex. Nature Communications, 7, 1-10. doi:

1118 10.1038/ncomms 13195

1119

1120 Vitalis, R., Gautier, M., Dawson, K. J., \& Beaumont, M. A. (2014). Detecting and measuring

1121 selection from gene frequency data. Genetics, 196(3), 799-817. doi:

$112210.1534 /$ genetics.113.152991.

1123

1124 Wagner, W. (1955). Die Bewertung morphologischer Merkmale in den unteren taxonomischen

1125 Kategorien, aufgezeigt an Beispielen aus der Taxionomie der Zikaden. Mitteilungen aus den

1126 Hamburgischen Zoologischen Museum and Institut, 53, 75-108.

PeerJ reviewing PDF | (2020:09:53180:2:0:NEW 14 Apr 2021) 
1127

1128 Wagner, W. (1959). IX. Teil Homoptera. In Zoologische Studien in Westgriechenland. Wien.

1129 Springer-Verlag, pp. 583-605.

1130

1131 Weaver, C., \& King, D., (1954). Meadow Spittlebug. Research Bulletin, Ohio Agricultural

1132 Experiment Station, 741, pp. 99

1133

1134 Werren, J. H., Baldo, L., \& Clark, M. E. (2008). Wolbachia: master manipulators of invertebrate 1135 biology. Nature Reviews. Microbiology, 6, 741-751. doi: 10.1038/nrmicro1969.

1136

1137 Whitworth, T. L., Dawson, R. D., Magalon, H., \& Baudry, E. (2007). DNA barcoding cannot 1138 reliably identify species of the blowfly genus Protocalliphora (Diptera: Calliphoridae).

1139 Proceedings of the Royal Society B: Biological Sciences, 274, 1731-1739. doi:

$1140 \quad 10.1098 / \mathrm{rspb} .2007 .0062$.

1141

1142 Wickham, H. (2016). ggplot2: elegant graphics for data analysis. Springer: Verlag, New York. 1143

1144 Wolf, J. B. W., \& Ellegren, H. (2017). Making sense of genomic islands of differentiation in 1145 light of speciation. Nature Reviews Genetics, 18, 87-100. doi: 10.1038/nrg.2016.133.

1146

1147 Wu, C.-I. (2001). The genic view of the process of speciation. Journal of Evolutionary Biology, 1148 14, 851-865. doi: 10.1046/j.1420-9101.2001.00335.x.

1149

1150 Yoon, J.-.I., Hrynkiv, V., Morano, L., Nguyen, A. T., Wilder, S., Mitchell, F. (2014).

1151 Mathematical modelling of glassy-winged sharpshooter population. Mathematical Biosciences 1152 and Engineering, 11, 667-677. doi: 10.3934/mbe.2014.11.667.

1153

1154 Yurtsever, S. (2002). Hybrid crosses of the meadow spittlebug Philaenus spumarius (L.)

1155 (Homoptera: Cercopidae) between New Zealand and Welsh populations. New Zealand Journal 1156 of Zoology, 29, 245-251. doi: 10.1080/03014223.2002.9518308. 
1158

1159 Zheng, X., Levine, D., Shen, J., Gogarten, S. M., Laurie, C., \& Weir, B. S. (2012). A high-

1160 performance computing toolset for relatedness and principal component analysis of SNP data.

1161 Bioinformatics, 28(24), 3326-3328. doi: 10.1093/bioinformatics/bts606.

1162

1163

1164 


\section{Figure 1}

Map with the sampling locations of Philaenus.

The points indicate the sampling locations of Philaenus spumarius in Turkey (TUR), Greece (GRE), Finland (FIN), France (FRAN), Portugal (POR), United Kingdom (UK), Azores (AZO) and United States of America (USA), and of Philaenus tesselatus in Morocco (MOR). In Morocco, three locations were sampled (details in Supplementary Table S1).
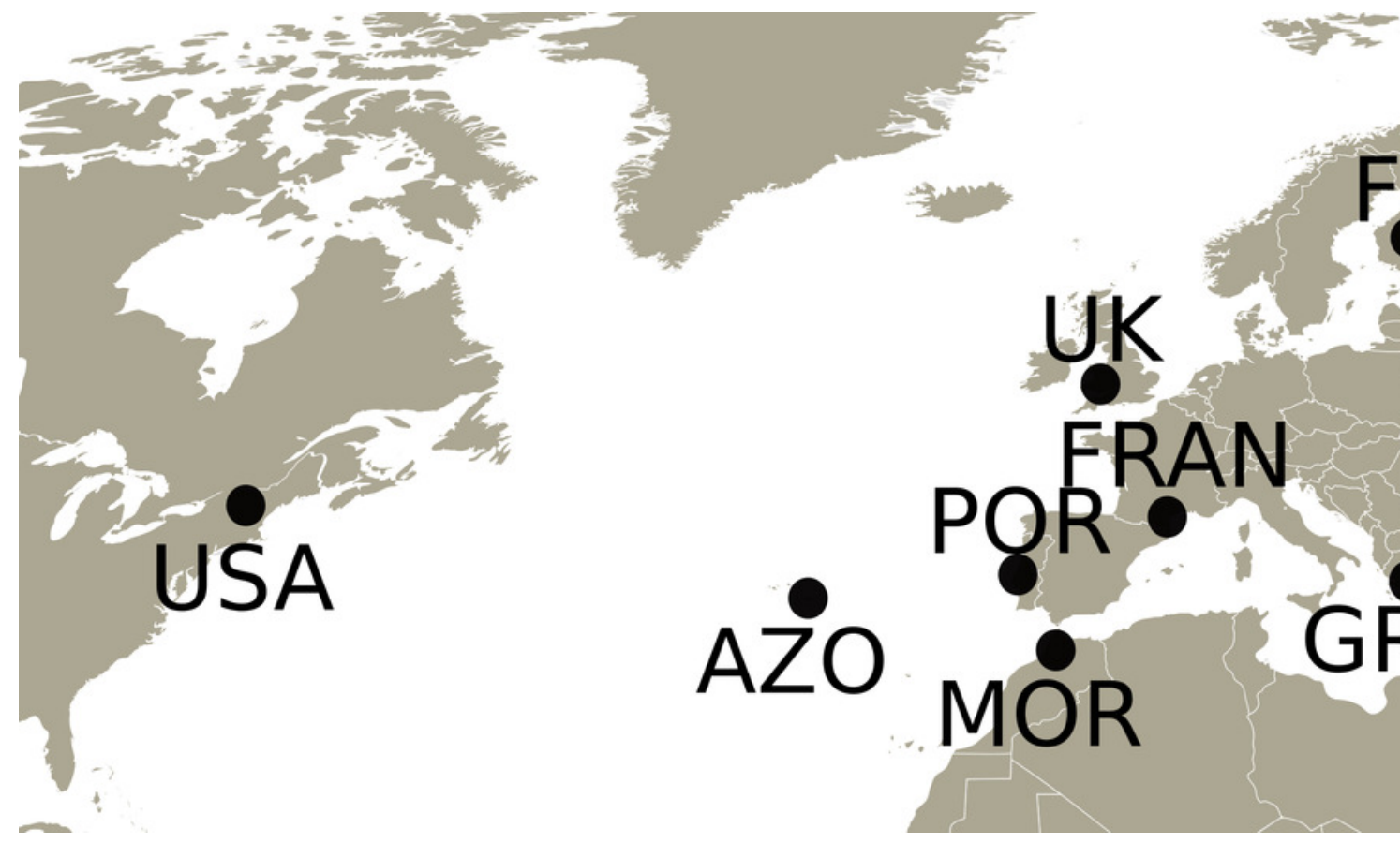
Figure 2

Schematic representation of the aedeagus of Philaenus with morphometric characteres measured

(A) Morphometric characters measured on the aedeagus of Philaenus spittlebugs: TotLen total length of aedeagus; LowLen - length of lower appendages (left and right); MidLen length of middle appendages (left and right); UpLen - length of upper appendages (left and right); UpCur - curvature of upper appendages (left and right). (B) Diagram of geometric measurements of the curvature of the aedeagus upper appendages.
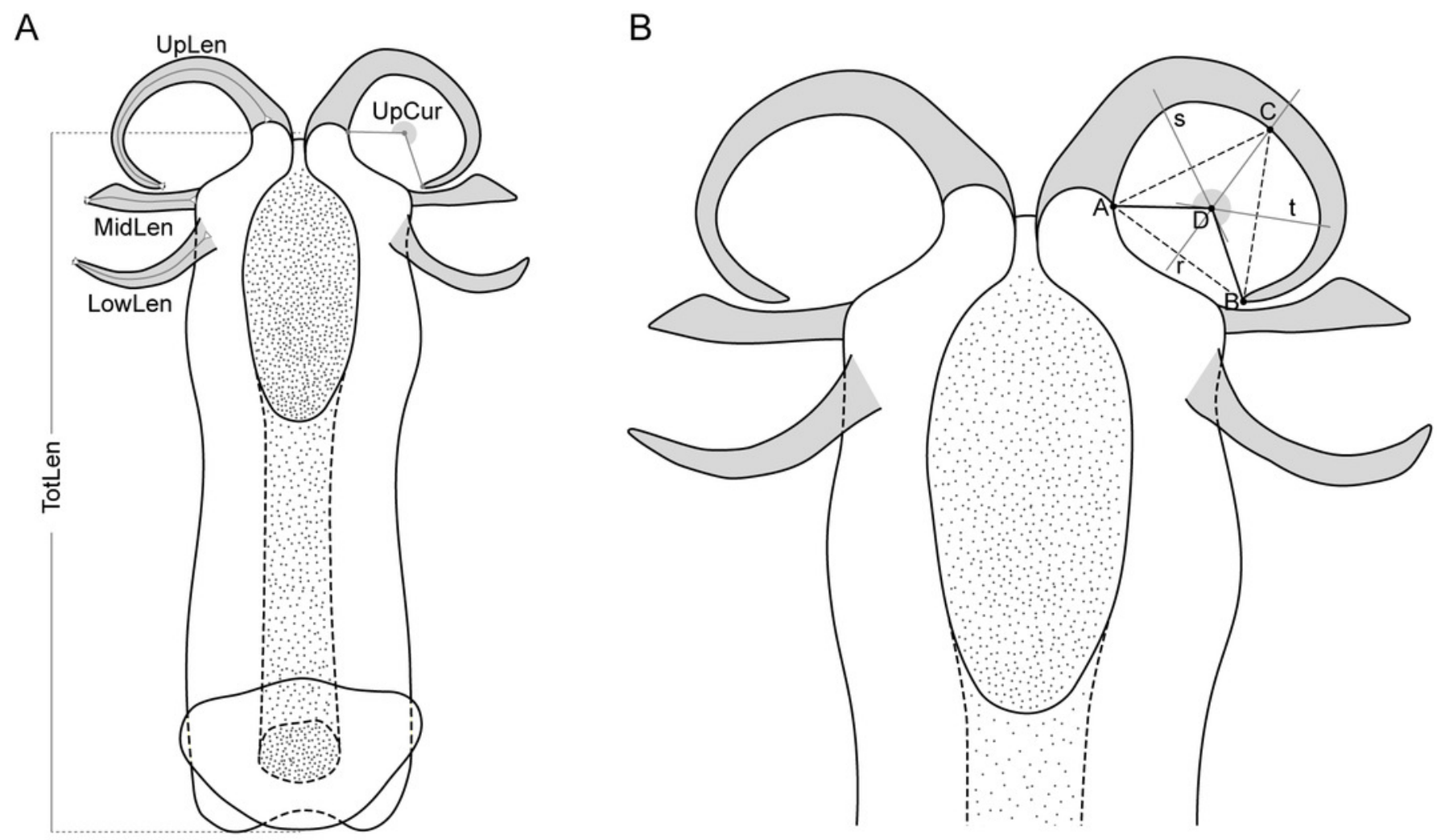
Figure 3

Principal component analysis of morphometric data of male aedeagus and of RAD-seq data.

Scatterplots of the three first principal components (PC1, PC2 nd PC3) from the Principal Component Analysis (PCA) of morphometric data of male aedeagus ( $A$ and $B$ ) and of RAD-seq data (C and D).
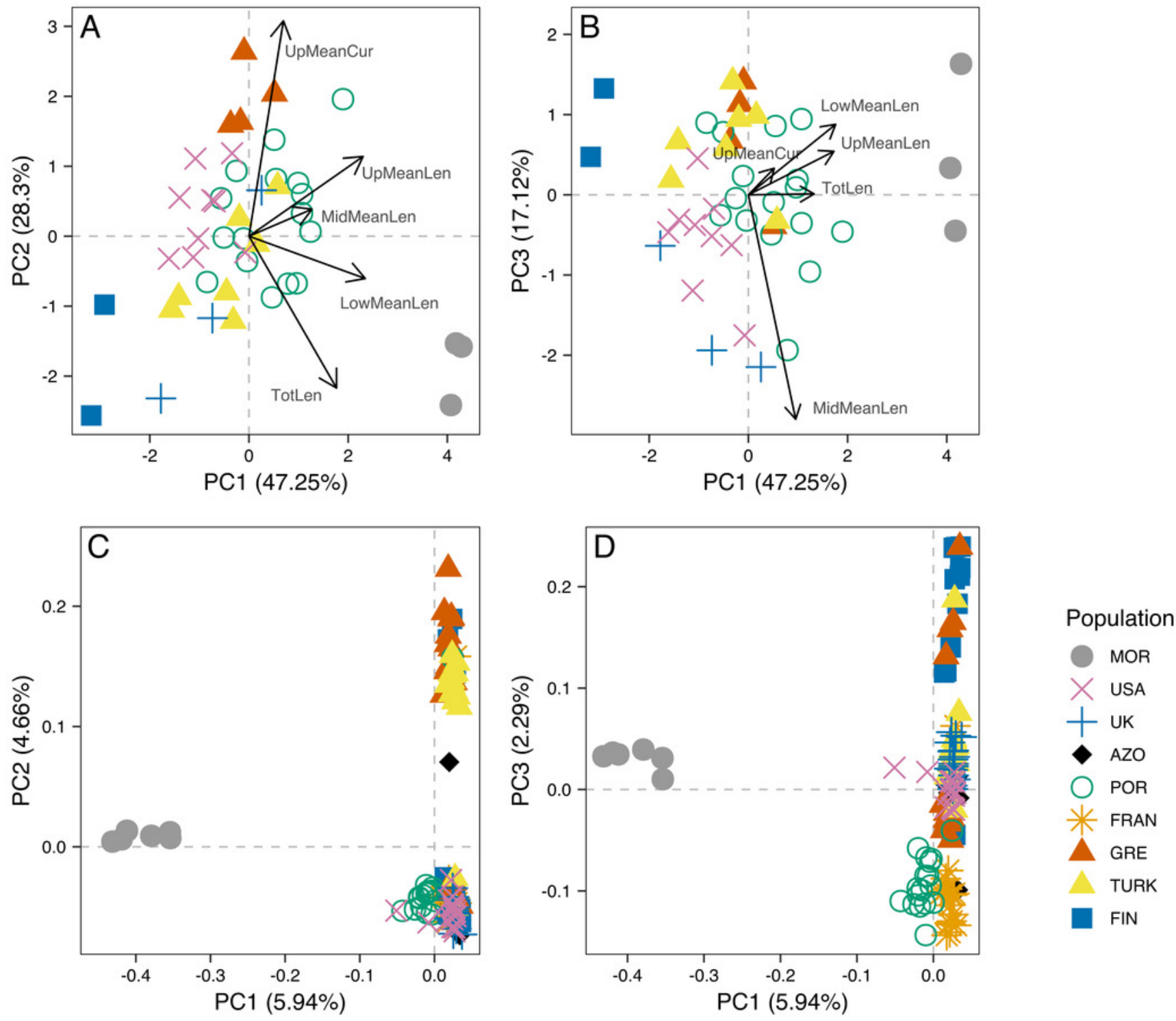


\section{Figure 4}

STRUCTURE results for the complete dataset with 9 populations

STRUCTURE results for the dataset including all populations, for $K=2$ to $K=5$. The best $K$ according to Evanno et al. (2005) method was $K=4$. The colours of the major groupings in STRUCTURE were chosen to correspond loosely to the mitochondrial DNA haplogroups (Rodrigues et al., 2014 and this study), for a better visualization.

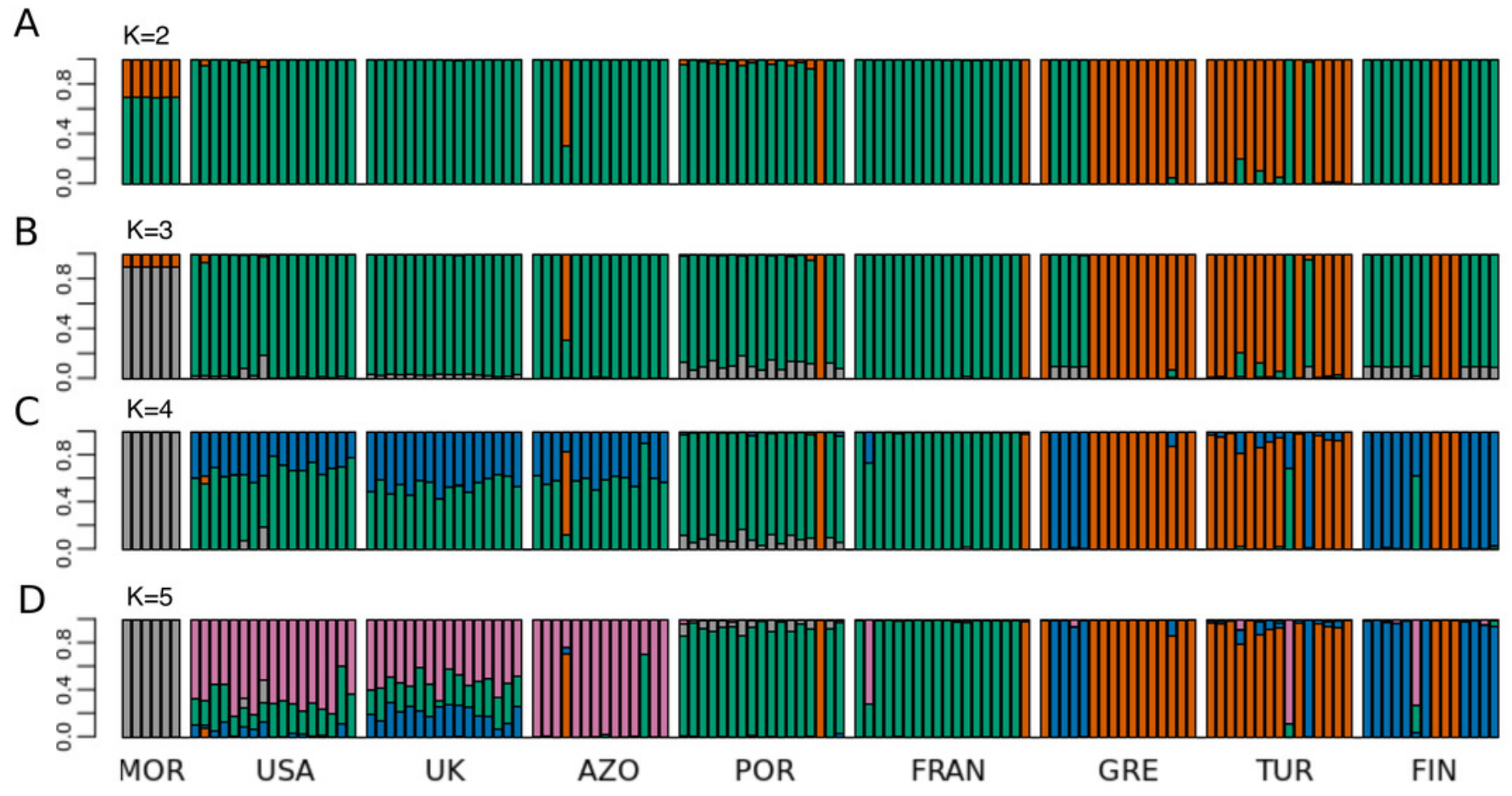




\section{Figure 5}

Geographical distance versus genetic distance for each pair of populations

Scatterplot of the geographical distance (natural logarithm) versus genetic distance $\left(\mathrm{F}_{\mathrm{ST}} /(1-\right.$ $\left.\mathrm{F}_{\mathrm{ST}}\right)$ ) for each pair of populations. Colours discriminate distances between: Morocco and the other populations (circles); European populations (diamond); transatlantic populations (USA or Azores) vs. European populations (crosses). 


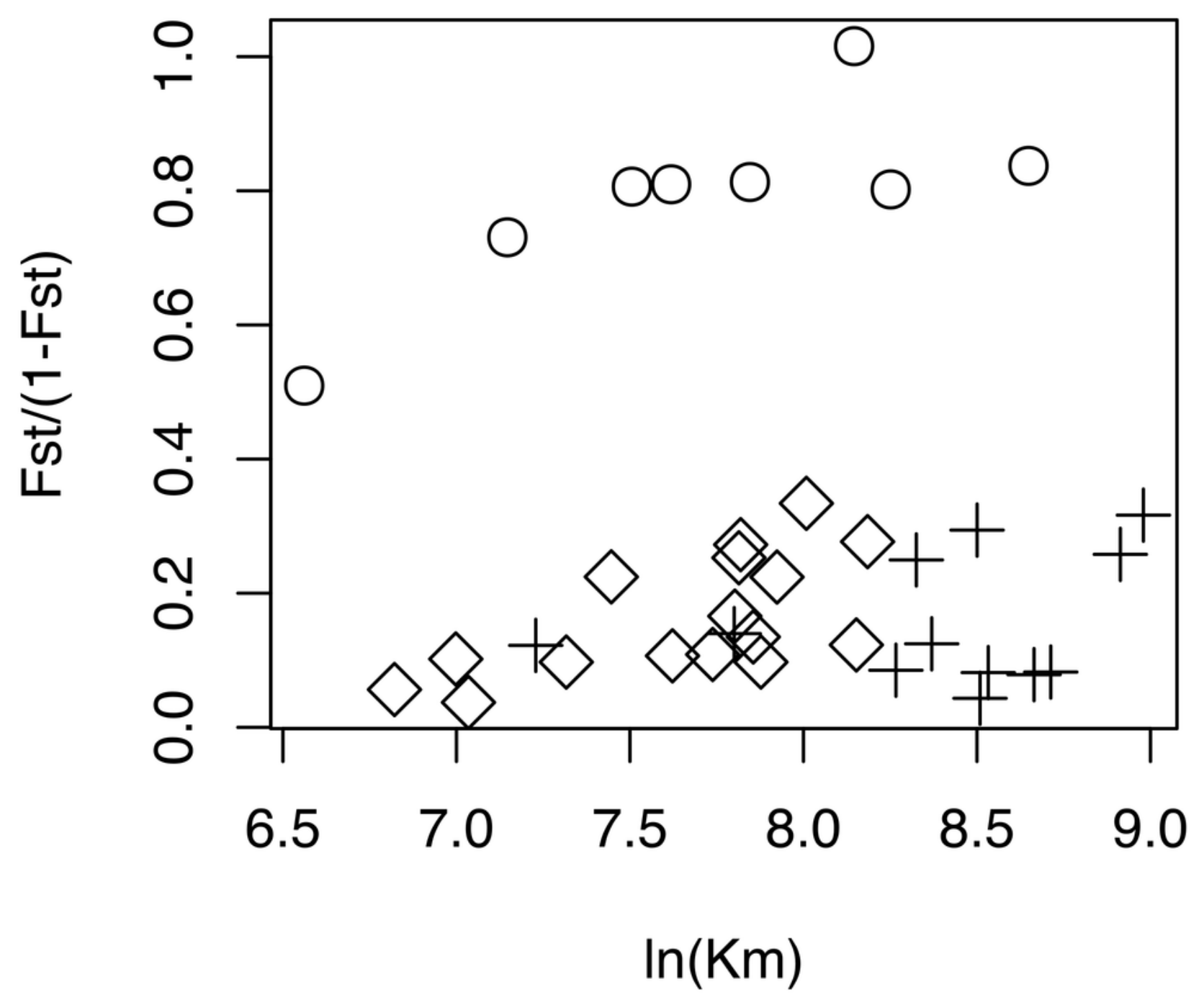




\section{Figure 6}

Population genetic structure analysis, excluding the North African population.

(A) Scatterplot of the two first principal components (PC1 and PC2) from the Principal Component Analysis of RAD-seq data for the 8 populations, after excluding the North African population; (B) STRUCTURE results for $K=3$ (best $K$ according to Evanno et al., 2005). (C) Mitochondrial haplogroups present in each population (Rodrigues et al., 2014 and this study) shown in coloured squares (blue: "North-Eastern", green: “Western"; red: “EasternMediterranean"). The colours of the major groupings in STRUCTURE were chosen to correspond loosely to the mitochondrial DNA haplogroups, for a better visualization

A
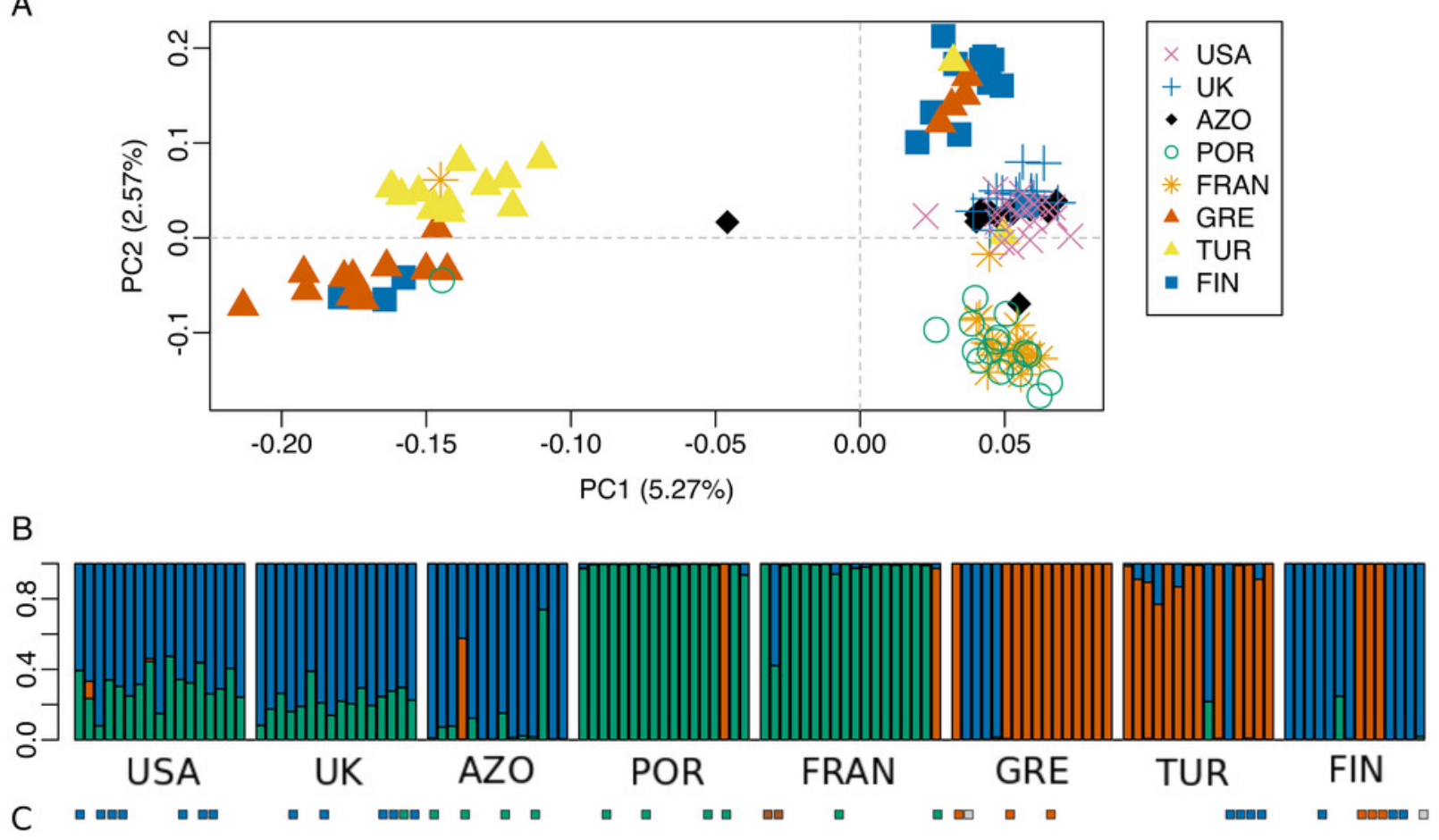


\section{Table $\mathbf{1}$ (on next page)}

Pairwise $F_{S T}$ matrix and estimates of expected and observed heterozygosity $\left(H_{E}\right.$ and $H_{0}$, respectively) and $F_{15}$ for each population.

The triangular matrix shows the $F_{S T}$ values for each pair of populations and the bottom values are the estimates of expected and observed heterozygosity $\left(H_{E}\right.$ and $H_{0}$, respectively) and $F_{\text {IS }}$ for each population. 


\begin{tabular}{cccccccccc} 
& MOR & USA & UK & AZO & POR & FRAN & GRE & TUR & FIN \\
\hline MOR & 0 & & & & & & & & \\
USA & 0.4557 & 0 & & & & & & & \\
UK & 0.4474 & 0.0415 & 0 & & & & & & \\
AZO & 0.4464 & 0.0785 & 0.0980 & 0 & & & & & \\
POR & 0.3375 & 0.0755 & 0.0887 & 0.1089 & 0 & & & \\
FRAN & 0.4222 & 0.0728 & 0.0925 & 0.1226 & 0.0359 & 0 & & \\
GRE & 0.4484 & 0.2050 & 0.2141 & 0.1998 & 0.1831 & 0.1833 & 0 & & \\
TUR & 0.5039 & 0.2403 & 0.2503 & 0.2273 & 0.2168 & 0.2018 & 0.0533 & 0 & \\
FIN & 0.4451 & 0.0762 & 0.0964 & 0.1108 & 0.1094 & 0.1188 & 0.0887 & 0.1423 & 0 \\
\hline
\end{tabular}

\begin{tabular}{cccccccccc} 
& MOR & USA & UK & AZO & POR & FRAN & GRE & TUR & FIN \\
\hline He & 0.0373 & 0.0708 & 0.0737 & 0.0641 & 0.0795 & 0.0725 & 0.0808 & 0.0789 & 0.0781 \\
Ho & 0.0258 & 0.0460 & 0.0537 & 0.0460 & 0.0406 & 0.0475 & 0.0360 & 0.0491 & 0.0396 \\
FIS & 0.3313 & 0.2927 & 0.2379 & 0.2599 & 0.4421 & 0.2962 & 0.4795 & 0.3544 & 0.4233
\end{tabular}

1 